\title{
The More Supply Chain Control Power, the Better? A Comparison among Four Kinds of Cooperation Models
}

\author{
Weihua Liu, Shuqing Wang, and Donglei Zhu \\ College of Management and Economics, Tianjin University, No. 92, Weijin Road, Nankai District, Tianjin 300072, China \\ Correspondence should be addressed to Weihua Liu; lwhliu888@163.com
}

Received 25 May 2015; Accepted 13 September 2015

Academic Editor: Lionel Amodeo

Copyright ( 2015 Weihua Liu et al. This is an open access article distributed under the Creative Commons Attribution License, which permits unrestricted use, distribution, and reproduction in any medium, provided the original work is properly cited.

\begin{abstract}
This paper introduces the parameter of supply chain control power into existing supply chain coordination models and explores the impacts of control power on the profits of manufacturer, retailer, and the overall supply chain under four modes of decisionmaking, including the decentralized decision-making dominated by manufacturer, the decentralized decision-making dominated by retailer, centralized decision-making, and Nash negotiation decision-making. Some significant conclusions are obtained. Firstly, supply chain control power does have great impact on the supply chain profits. The profit of the whole supply chain with centralized decision-making is higher than those of the other three modes, while the overall profit of supply chain with decentralized decisionmaking is superior to the profit when retailer and manufacturer dominate the supply chain together. Secondly, with decentralized decision-making, for manufacturer and retailer, it is beneficial to gain the control powers of the supply chain; however, control power has an optimal value, not the bigger, the better. Thirdly, under certain circumstances, order quantity will increase and the wholesale price will decrease when control power is transferred from manufacturer to retailer. In this case, the total profit of supply chain dominated by retailer will be greater than that dominated by manufacturer.
\end{abstract}

\section{Introduction}

As commonly known, the core of supply chain management is cooperation and coordination [1]. The member enterprises in the supply chain should carry out long-term cooperation by establishing strategic partnerships [2]. However, the problem of supply chain control power management exists in all supply chains [3]. Control power refers to the owner having the right to decide how the items are used [4]. Therefore, supply chain control power is the power of supply chain members to dominate the supply chain decisions. Taking a two-echelon supply chain involving one supplier and one retailer, for example, if the manufacturer dominates the supply chain, the retailer will be in a passive ordering strategy position as its control power is smaller than that of the manufacturer. On the contrary, if the supply chain is dominated by the retailer, the manufacturer will have a passive supply strategy. The control power difference has a significant impact on product pricing, ordering quantity of the supply chain, and the cooperation performance of supply chain members. Thus, the fight for supply chain control powers has been a common problem between supply chain members, which makes supply chains unstable. For example, Procter \& Gamble and Wal-Mart's contention for control powers around the commodity prices and shelf location in the 1980s has become a classic case of supply chain control. The same thing happened in March 2004 in China, when a showdown broke out between the powerful air-conditioner manufacturer GREE and the dominant Electric Appliances Chain Stores (EACS), GOME. As a result, GOME headquarters ordered all of its stores to stop selling GREE air-conditioners once inventory was cleared. Finally, the alliance between GREE and GOME ended after several rounds of fruitless negotiations [5]. Obviously, from the view of practice, the allocation of supply chain control powers among different members is of great significance to the sustainability of the supply chain cooperation. Moreover, the rational design of control power is also an important consideration when a new supply chain is built.

However, from the point of theory research development, the research of supply chain control power is relatively lacking, and the concept of control parameter has not been introduced in the existing literature. Most studies assume that 
the supply chain is a typical Stackelberg game and leaders have absolute control of the supply chain, while followers have no control at all [6-12]. However, in practice, followers in the supply chain just have less control power than the leader instead of having no control. Therefore, these studies do not take the impact of control parameters on the decisionmaking results into account. Another part of those studies emphasizes the equal status of cooperation between members of the supply chain, such as supply chain cooperation research based on the situation where manufacturers and retailers are in the same decision-making positions. Overall, these previous studies neither consider the impact of control power on the decision-making results nor take how to choose the best control power in different cooperation models into account. Thus, from a theoretical point of view, it is also urgently necessary to carry out specialized research and systematically explore the impact of supply chain control power on the decision results in different modes.

This study will help managers and researchers understand the impact of supply chain control power parameters on the supply chain operational performance in a new or an existing supply chain operation. We will analyze the optimal control power of the supply chain under different modes of cooperation and then compare the optimal control power and corresponding supply chain performance under different cooperation models. In order to facilitate the research, this paper studies a two-echelon supply chain with one supplier and one retailer based on Demirkan and Cheng and Seifert et al. $[6,13]$. Different from these two studies, we intend to introduce the parameter of supply chain control power to study the problem of supply chain coordination in different cooperation models. The following issues are going to be addressed:

(1) According to the difference of control power allocations, there are four decision-making modes in supply chains, including decentralized decision-making dominated by manufacturers, decentralized decisionmaking dominated by retailers, centralized decisionmaking, and Nash negotiation decision-making. What effects will the control power have on the order volume, the wholesale price, and the profits of manufacturers, retailers, and the overall supply chain in four modes?

(2) Will the leader gain more profits if it has greater control power of the supply chain? Will there be any optimal control power? Will the supply chain performance be greater when the control power of the supply chain members is equivalent?

(3) For the enterprises in different positions of the supply chain, how does one apply this paper's conclusion to better manage or participate in a supply chain?

Many unexpected conclusions have been obtained in this study. For example, there exists an optimal control power, beyond which control becomes detrimental, in both manufacturer-dominated and retailer-dominated supply chain. The total profits of the supply chain in decentralized decision-making are greater than the profits when the retailer and the manufacturer own equivalent control power, which is the poorest among the four different modes of cooperation. When the supply chain control power transfers from the manufacturer to the retailer, order volume and the profit will increase while the wholesale price will decrease compared to the supply chain dominated by the manufacturer. This also explains why retailer-dominated supply chains (such as the Wal-Mart-dominated supply chain) have increasingly become a popular form of supply chain collaboration in today's fierce market competition.

The rest of this paper is organized as follows. Section 2 reviews the literature related to supply chain control power. Section 3 gives the problem description and assumption used in this paper. Section 4 provides four supply chain models, which are Model 1 (supply chain dominated by manufacturer with decentralized decision), Model 2 (supply chain dominated by retailer with decentralized decision), Model 3 (supply chain with centralized decision), and Model 4 (supply chain dominated by both manufacturer and retailer). The allocations of control power and order quantity while realizing supply chain coordination are also given in this section. Section 5 compares the four models. Section 6 proposes the conclusions and management connotations of this model.

\section{Literature Review}

In recent years, the literature has been more dedicated to the coordination strategy of supply chain management in order to help improve the overall supply chain performance and the correlation between manufacturers and retailers. Considering the existing relevant studies, the following four main aspects of supply chain research will be included: (1) coordination dominated by the manufacturer, (2) coordination dominated by the retailer, (3) coordination under centralized decision, and (4) coordination dominated by both manufacturer and retailer. On this basis, we compare the supply chain coordination according to these four types of supply chain control modes.

2.1. Research of Supply Chain Coordination Dominated by Manufacturer. Generally, manufacturers have been considered as the center of supply chain [14]. Many successful manufacturers occupy a pivotal position in their respective distribution channels, such as GE, GM, Sony, and Philips. Many scholars have done a lot of explorations of supply chain coordination led by manufacturers. For example, Qin and Yang considered a supply chain involving one leading supplier and one following retailer in which a revenuesharing contract is adopted [15]. Yu et al. assumed that the manufacturer and its retailers have a leader-follower relationship, and they found out that the manufacturer can benefit from its leadership and monopolize the added profit of the VMI system in some cases [16]. Yu et al. studied a Stackelberg game, where the manufacturer is the leader and the retailers are followers [17]. They then discussed how a manufacturer and its retailers interact with each other in order to optimize their individual net profits by adjusting product marketing (advertising and pricing) and inventory 
policies in an information-asymmetric VMI (vendor managed inventory) supply chain.

\subsection{Research of Supply Chain Coordination Dominated by} Retailer. In the past two decades, due to retailers adopting marketing methods actively in business, the nature and role of orders made by the retailer's brand marketing strategy have changed [18]. In the studies of supply chain coordination dominated by retailers, some scholars have studied manufacturer's strategies [19], multiple retailers' price competition [20], retailers' control strategy in uncertain environments [21], and the supply chain coordination research dominated by retailers [22]. However, these studies did not introduce the concept of control power parameters, assuming that only retailers have the power to dominate the market price or quantity of goods while manufacturers only have the power to accept it passively without any control power.

For example, Raju and Zhang suggested that the real trade today is increasingly dominated by large, centrally managed "power" retailers, and then developed a channel model in the presence of a dominant retailer to examine how a manufacturer can best coordinate such a channel [19]. Geylani et al. proposed that the growing dominance of large retailers has altered traditional channel incentives for manufacturers and built a model in which a dominant and a weak retailer compete for the sale of a single product supplied by a single manufacturer [20]. Pan et al. considered that retailing channels are increasingly being dominated by "power" retailers who are in a position to dictate prices and ordering schedules to manufacturers and suppliers [21]. In their study, they also considered this scenario and constructed a two-period model to discuss pricing and ordering problems for a dominant retailer with demand uncertainty in a declining price environment. Chen and Xiao developed two coordination models of a supply chain consisting of one manufacturer, one dominant retailer, and multiple fringe retailers to investigate how to coordinate the supply chain after demand disruption [22]. Finally, they found that the disrupted amount of demand largely affects the allocation of the supply chain's profit.

\subsection{Research of Supply Chain Coordination under Central-} ized Decision. Centralized decision-making refers to the enterprise consisting of different members of the making supply chain decisions. In centralized decision-making, one member cannot control another because there are no control parameters among the supply chain members. Generally speaking, centralized decision-making is better than decentralized decision-making. Cachon showed that there is no such competitive strategy between independent supply chain agents that can achieve the optimal overall supply profit [23]. When all agents cooperate to maximize the overall supply chain profit as well as each party's profit, a number of coordination strategies can be implemented. Therefore, centralized decision-making is often used to check the performance of the different modes of cooperation as a measure of supply chain coordination. There are many investigations of supply chain coordination under centralized decision-making. For example, Aviv and Federgruen studied three different collaborative structures, which include no information sharing, information sharing without synergy, and information sharing under centralized decision-making [24]. Seifert et al. proposed that many manufacturers have started to use virtual stores as a direct distribution channel in addition to their existing indirect retail channels and analyzed this problem from a supply chain perspective by developing and solving mathematical models for both a dedicated and an integrated supply chain [25].

\subsection{Research of Supply Chain Coordination Dominated by} Both Manufacturer and Retailer. The condition in which supply chain members have equal control power is a typical coordination research of NASH negotiation game mode, where the supply chain members make decisions, respectively. Coordination methods in this case have been studied by many scholars. By considering a general arbitration scheme, Nash proved that the bargaining solution can be uniquely determined [26]. Then, Roth provided a generalized Nash bargaining (GNB) game, which considered the bargaining power based on Nash [27]. Nash negotiation has since been used in many studies [28]. Ye and Li demonstrated the nonreasonability of the buy-back contract mechanism of traditional supply chains and put forward to adopt the Stackelberg model and Nash negotiation model to design a buy-back contract [29]. Nagarajan and Bassok discussed the negotiation power in supply chains via GNB game and predicted at equilibrium the structure of the supply chain as a function of the players' relative negotiation power [28]. Hezarkhani and Kubiak studied a supply chain with two independent companies producing an identical product and cooperating through transshipment [30]. Using the GNB, they derived coordinating transshipment prices that always gave rise to a coordinating contract for the chain. By building a revenue sharing mechanism, the coordination mechanism with Shapley value method, and an asymmetric Nash negotiation mechanism, supply chain members are motivated to respond positively to the cooperation in producing and marketing green products [31]. Sheu and Gao investigated how bargaining power affects negotiations between manufacturers and reverse logistics providers in reverse supply chains [32]. Utilizing the asymmetric Nash bargaining game, this work seeks equilibrium negotiation solutions. The above literature has done beneficial exploration in different cases of the Nash negotiation model, some related methods of which can be used for reference in this paper.

\subsection{Comparison of Supply Chain Coordination under Different} Cooperation Models. In recent years, many scholars have compared the results of supply chain coordination under different modes of cooperation, where the representatives are Demirkan and Cheng, Lu et al., Seifert et al., and Wei et al. $[6,13,33,34]$. In these studies, it is assumed that the one who dominates the party has full control, while participants do not have any control power. For example, Demirkan and Cheng studied an application services supply chain consisting of one application service provider (ASP) and one application infrastructure provider (AIP) and they found an effective decentralized mechanism to achieve the goal of maximizing 
the overall supply chain performance and that it is better to let the player closest to the market coordinate the supply chain [6]. In Lu et al., a supply chain system composed of one manufacturer and one retailer was established for the analysis and comparison on the level of supply chain performance among three cases: the centralized decision-making supply chain, the supply chain with manufacturers having pricing power, and the supply chain with retailers having pricing power [33]. Seifert et al. considered the following cases: no coordination among any members of the supply chain (decentralized), coordination between only two members (sub-supply chain coordination), and coordination of the whole supply chain as a benchmark [13]. Wei et al. studied two decentralized supply chains, where retail prices were determined by the supplier or the retailers. For each model, they derived and characterized the equilibrium by transforming the game problem into an optimization problem [34].

These studies explored beneficially the way of supply chain control in different control modes; however we can still find some shortcomings. For example, although dominant member has more control power when making supply chain decisions, other participants also have certain control power. Therefore, the existing studies do not take into account the impact of control power differences between supply chain members in the decision-making.

Based on Demirkan and Cheng and Seifert et al., this paper will introduce the control power parameter into supply chain coordination $[6,13]$. Moreover, supply chain coordination problems in different modes of cooperation and the influence of supply chain control parameters on the decisionmaking result will be explored. This paper focuses on the effects control power parameters have on the order quantity, wholesale price, and the profits of supply chain members in four kinds of conditions (dominated by the manufacturer with decentralized decision-making, dominated by the retailer with decentralized decision-making, with centralized decision-making, and dominated by both the manufacturer and retailer), in order to provide necessary strategy reference for the allocation of control power between the manufacturer and retailer.

\section{The Problem Description and Assumptions}

A two-echelon supply chain consisting of a single manufacturer and a single retailer is considered In a decision cycle, there is punishment cost coming from the shortage of products sold to customers, and the manufacturer prepares production capacity and output according to the retailers' order quantity before the selling season. It is assumed that the demand faced by retailer is $D$, while $F(x)$ is its cumulative distribution function, and $f(x)$ is its probability density function, $\bar{F}(x)=1-F(x)$. If the manufacturer's control power is set to be $\beta$, then the control power of the retailer is $t=1-\beta$. In order to build models conveniently, the following important assumptions are made.

Assumption 1. Whoever owns the control power can dominate the wholesale price [35].
Assumption 2. Manufacturer will provide a subsidy to the retailer, representing the inventory subsidies of unsold goods at the end of season [36]. For manufacturer to own more control power, we assume that the bigger the control power is the greater the subsidy he is willing to provide to the retailer will be. We set $\lambda$ as the coefficient of subsidies manufacturer provides to retailer; then the subsidy will be $\lambda \beta I(q)$. In reality, we can determine $\lambda$ by measuring different sets of $\beta$ and remaining stock $I(q)$ as well as the real value of subsidies and then obtain $\lambda$ using the method of LSE (least squares estimation) [37].

Assumption 3. As the dominant position of a core business in the supply chain will lead to an unequal position for other partners, supply chain leaders may harm the interests of other partners when they pursue their own interests and thus affect the positivity of their partners resulting in cooperation risks. The one who owns control power must bear corresponding risk cost and the more the control power and order quantity, the more the risk costs, no matter who the retailer or manufacturer is. Meanwhile, when the control power one supply chain member owns increases, the fight for the power will be fierce, resulting in more risk cost to gain one more unit control power; thus the marginal change rate of the risk cost increases with the control power. According to the assumption of Iossa and Martimort [38] and Greco [39], it is assumed that there is no difference in the cost coefficient of control power between manufacturer and retailer, so we set the cost coefficient of manufacturer and retailer which are both $k$. So the risk cost of manufacturer is $(k / 2) \beta^{2} q_{i}$ and that of retailer is $(k / 2) t^{2} q_{i}=(k / 2)(1-\beta)^{2} q_{i}$.

Assumption 4. When a manufacturer and a retailer implement centralized decision-making, they will take on the market risk together without risk costs.

The model parameters and variables are summarized in the following list.

$c_{s}$ : manufacturer's production cost per unit quantity.

$c_{r}$ : retailer's cost of sales per unit.

$g$ : retailer's cost per unit due to the shortage of goods.

$p$ : product price per unit (determined by the market).

$\mu$ : average market demand.

$q_{i}$ : retailer's order quantity/manufacturer's production quantity in model $i(i=1,2,3,4)$.

$q_{i}{ }^{*}:$ retailer's optimal order quantity/manufacturer's optimal production quantity in model $i(i=1,2,3,4)$.

$S(q)$ : retailer's expected sales quantity.

$I(q)$ : expected inventory quantity.

$L(q)$ : expected shortage quantity.

$w_{i}$ : product wholesale price in model $i(i=1,2,3,4)$.

$w_{3}{ }^{\max }$ : upper limit of the optimal wholesale price in Model 3.

$\beta$ : manufacturer's control power, $t=1-\beta$. 
$\beta_{i}{ }^{*}$ : optimal control power in model $i(i=1,2,3,4)$.

$t$ : retailer's control power, $t=1-\beta$.

$k$ : cost coefficient of control power.

$\lambda$ : coefficient of subsidies manufacturer provides to retailer.

$(k / 2) \beta^{2} q_{i}$ : manufacturers' risk cost when they make decisions alone.

$(k / 2) t^{2} q_{i}$ : retailers' risk cost when they make decisions alone, $(k / 2) t^{2} q_{i}=(k / 2)(1-\beta)^{2} q_{i}$.

$\pi_{m}$ : manufacturer's profit function.

$\pi_{m i}{ }^{*}$ : manufacturer's optimal profit in model $i$ ( $i=$ $1,2,3,4)$.

$\pi_{r}$ : retailer's profit function.

$\pi_{r i}{ }^{*}$ : retailer's optimal profit in model $i(i=1,2,3,4)$.

$\pi_{3}$ : profit of overall supply chain in Model 3 .

Note that $i=1,2,3,4$, respectively, represent Models $1-4$.

Then, according to the above problem description and assumptions, the following formulas can be obtained before modeling.

Quantity of the retailer's expected sales is as follows:

$$
S(q)=E(\min (q, D))=q-\int_{0}^{q} F(x) d x .
$$

Expected inventory quantity is as follows:

$$
I(q)=E(q-D)^{+}=q-S(q) .
$$

Quantity of the expected shortage is as follows:

$$
L(q)=E(D-q)^{+}=\mu-S(q)=\mu-q+\int_{0}^{q} F(x) d x .
$$

Result of differentiating $S(q)$ and $I(q)$ is as follows:

$$
\begin{aligned}
& \frac{\partial S(q)}{\partial q}=1-F(q)=\bar{F}(q), \\
& \frac{\partial I(q)}{\partial q}=1-(1-F(q))=F(q) .
\end{aligned}
$$

\section{Model Building}

In this section, decision-making carried out by the manufacturer and retailer occurs under four modes. Model 1 (dominated by the manufacturer with decentralized decisionmaking), Model 2 (dominated by the retailer with decentralized decision-making), Model 3 (centralized decisionmaking), and Model 4 (dominated by both the manufacturer and retailer) will be discussed, respectively. We will study the decisions of the manufacturer and retailer under our models, and then the corresponding optimal wholesale price and optimal purchase amount will be given and optimal control power will be determined. Finally, a comparison will be made among the results of the decision modes.
4.1. Model 1: Supply Chain Dominated by Manufacturer with Decentralized Decision. In this case, it is assumed that, under the manufacturer's control power $\beta>0.5$, the manufacturer decides the wholesale price and control power $\beta$, while the order quantity is determined by the retailer. Then, the manufacturer and retailer present a typical Stackelberg game, in which the manufacturer is the leader and the retailer is the follower. Finally, a reverse solving method can be used to solve the model.

(1) Retailer Makes the Decision. The profit function of the retailer is

$$
\begin{aligned}
\pi_{r 1}\left(q_{1}\right)= & p S\left(q_{1}\right)-g L\left(q_{1}\right)-\left(c_{r}+w_{1}\right) q_{1}+\lambda \beta I\left(q_{1}\right) \\
& -\frac{k}{2}(1-\beta)^{2} q_{1},
\end{aligned}
$$

where the first section is the retailer's profit, the second is the retailer's loss, the third is the retailer's cost, the fourth is the subsidy the retailer obtains from the manufacturer, and the last one is the retailer's risk costs.

Take the first derivative of $q_{1}$ with respect to $\pi_{r 1}\left(q_{1}\right)$ and the following equation can be obtained:

$$
\begin{aligned}
\frac{\partial \pi_{r 1}\left(q_{1}\right)}{\partial q_{1}}= & (p+g-\lambda \beta)\left(1-F\left(q_{1}\right)\right) \\
& -\left(c_{r}+w_{1}-\lambda \beta\right)-\frac{k}{2}(1-\beta)^{2} .
\end{aligned}
$$

Then, take the second derivative of $q_{1}$ with respect to $\pi_{r 1}\left(q_{1}\right)$ which yields the following equation:

$$
\frac{\partial^{2} \pi_{r 1}\left(q_{1}\right)}{\partial q_{1}^{2}}=-(p+g-\lambda \beta) f\left(q_{1}\right)<0,
$$

which indicates that the retailer's expected profit is strictly a concave function on $q_{1}$.

Let

$$
\begin{aligned}
\frac{\partial \pi_{r 1}\left(q_{1}\right)}{\partial q_{1}}= & (p+g-\lambda \beta)\left(1-F\left(q_{1}\right)\right) \\
& -\left(c_{r}+w_{1}-\lambda \beta\right)-\frac{k}{2}(1-\beta)^{2}=0
\end{aligned}
$$

then

$$
\begin{aligned}
1- & F\left(q_{1}\right) \\
& =\frac{1}{(p+g-\lambda \beta)}\left[\left(c_{r}+w_{1}-\lambda \beta\right)+\frac{k}{2}(1-\beta)^{2}\right] .
\end{aligned}
$$


Hence,

$$
F\left(q_{1}\right)=\frac{p+g-c_{r}-w_{1}-(k / 2)(1-\beta)^{2}}{(p+g-\lambda \beta)} .
$$

Now, the optimal order quantity of retailer will be

$$
q_{1}{ }^{*}=F^{-1}\left(\frac{p+g-c_{r}-w_{1}-(k / 2)(1-\beta)^{2}}{(p+g-\lambda \beta)}\right) \text {. }
$$

Substitute (11) into (9), and let (9) be zero. Then, the response function $w_{1}\left(q_{1}{ }^{*}\right)$ of the wholesale price and $q_{1}{ }^{*}$ will be obtained; see the following:

$$
\begin{aligned}
w_{1}\left(q_{1}{ }^{*}\right)= & (p+g-\lambda \beta)\left(1-F\left(q_{1}{ }^{*}\right)\right)-\left(c_{r}-\lambda \beta\right) \\
& -\frac{k}{2}(1-\beta)^{2} .
\end{aligned}
$$

Take the first derivative of $q$ with respect to $w_{1}\left(q_{1}{ }^{*}\right)$; $\partial w_{1} / \partial q=-(p+g-\lambda \beta) f(q)$ can be gathered.

(2) Manufacturer Makes the Decision. The manufacturer determines two parameters; one is the wholesale price $w_{1}$, and the other is the optimal control power $\beta$.

Then, the profit function of the manufacturer is $\pi_{m 1}\left(q_{1}\right)=$ $\left(w_{1}-c_{s}\right) q_{1}-\lambda \beta I\left(q_{1}\right)-(k / 2) \beta^{2} q_{1}$, where the first one is income, the second one is the subsidy the manufacturer gives to the retailer, and the third one is the manufacturer's risk cost.
The manufacturer will determine the optimal wholesale price according to the retailer's order quantity $q_{1}$. Hence, taking the first derivative of $q_{1}$ with respect to $\pi_{m 1}\left(q_{1}\right)$ yields

$$
\begin{aligned}
\frac{\partial \pi_{m 1}\left(q_{1}\right)}{\partial q_{1}}= & \left(w_{1}-c_{s}\right)-\lambda \beta F\left(q_{1}\right)-\frac{k}{2} \beta^{2}+q \frac{\partial w_{1}}{\partial q_{1}} \\
= & (p+g-\lambda \beta) \bar{F}\left(q_{1}\right)\left(1-\frac{q_{1} f\left(q_{1}\right)}{\bar{F}\left(q_{1}\right)}\right) \\
& -\left(c_{r}-\lambda \beta\right)-\frac{k}{2}(1-\beta)^{2}-c_{s}-\lambda \beta F(q) \\
& -\frac{k}{2} \beta^{2} .
\end{aligned}
$$

Take the second derivative of $q_{1}$ with respect to $\pi_{m 1}\left(q_{1}\right)$ and we get

$$
\begin{aligned}
\frac{\partial^{2} \pi_{m 1}\left(q_{1}\right)}{\partial q_{1}{ }^{2}}= & -(p+g-\lambda \beta) \bar{F}\left(q_{1}\right) H\left(q_{1}\right) \\
& -(p+g-\lambda \beta) f\left(q_{1}\right)\left(1-\frac{q_{1} f\left(q_{1}\right)}{\bar{F}\left(q_{1}\right)}\right) \\
& -\lambda \beta f(q) .
\end{aligned}
$$

Here, we call $H\left(q_{1}\right)=q_{1} f\left(q_{1}\right) / \bar{F}\left(q_{1}\right)$ increasing generalized failure rate (IGFR) of the stochastic demand $D$. Namely, under the IGFR demand distribution, the general failure rate $H\left(q_{1}\right)$ is strictly increasing in $q$ if $F\left(q_{1}\right)<1$ [40]. The IGFR captures most common distributions, such as the normal, uniform, and the majority of Gamma and Weibull.

From Appendix A, the optimal $q_{1}{ }^{*}$ must satisfy

$$
F\left(q_{1}{ }^{*}\right)=\frac{p+g-c_{r}-c_{s}-(k / 2)(1-\beta)^{2}-(k / 2) \beta^{2}-q_{1}{ }^{*}(p+g-\lambda \beta) f\left(q_{1}{ }^{*}\right)}{p+g} .
$$

Then, the manufacturer's optimal wholesale price can be obtained from (12). Consider the following:

$$
\begin{aligned}
w_{1}\left(q_{1}{ }^{*}\right)= & (p+g-\lambda \beta)\left(1-F\left(q_{1}{ }^{*}\right)\right)-\left(c_{r}-\lambda \beta\right) \\
& -\frac{k}{2}(1-\beta)^{2} .
\end{aligned}
$$

Take the second derivative of $\beta$ with respect to $w_{1}\left(q_{1}\right)$ and we get

$$
\frac{\partial w_{1}\left(q_{1}\right)}{\partial \beta}=-\lambda\left(1-F\left(q_{1}\right)\right)+\lambda+k(1-\beta)
$$

Optimal control power of the manufacturer may be obtained by maximizing its revenue function. Thus, taking the first and second derivatives of $\beta$ with respect to $\pi_{m 1}\left(q_{1}\right)$ gives us

$$
\begin{aligned}
\frac{\partial \pi_{m 1}\left(q_{1}\right)}{\partial \beta}= & \frac{\partial w_{1}}{\partial \beta} q_{1}-\lambda I\left(q_{1}\right)-k \beta q_{1} \\
= & \left(-\lambda\left(1-F\left(q_{1}\right)\right)+\lambda+k(1-\beta)\right) q_{1} \\
& -\lambda\left(q_{1}-S\left(q_{1}\right)\right)-k \beta q_{1} \\
= & \left(\lambda F\left(q_{1}\right)+k(1-\beta)\right) q_{1}-\lambda \int_{0}^{q} F(x) d x \\
& -k \beta q_{1} \\
= & \lambda F\left(q_{1}\right) q_{1}+k q_{1}-\lambda \int_{0}^{q} F(x) d x \\
& -2 k \beta q_{1} .
\end{aligned}
$$


Due to $\partial^{2} \pi_{m 1}\left(q_{1}\right) / \partial \beta^{2}=-2 k q_{1}$, the optimal control power must satisfy

$$
\begin{aligned}
\frac{\partial \pi_{m 1}\left(q_{1}\right)}{\partial \beta}= & \lambda F\left(q_{1}\right) q_{1}+k q_{1}-\lambda \int_{0}^{q} F(x) d x \\
& -2 k \beta q_{1}=0 .
\end{aligned}
$$

Then $\beta$ can be solved by

$$
\begin{aligned}
\beta & =\frac{\lambda F\left(q_{1}\right) q_{1}+k q_{1}-\lambda \int_{0}^{q} F(x) d x}{2 k q_{1}} \\
& =\frac{1}{2}+\frac{\lambda\left(F\left(q_{1}\right) q_{1}-\int_{0}^{q} F(x) d x\right)}{2 k q_{1}} .
\end{aligned}
$$

So,

$$
\begin{aligned}
\beta & =\frac{1}{2}+\frac{\lambda\left(F\left(q_{1}\right) q_{1}-\int_{0}^{q} F(x) d x\right)}{2 k q_{1}} \\
& =\frac{1}{2}+\frac{\lambda}{2 k}\left(F\left(q_{1}\right)-\frac{1}{q_{1}} \int_{0}^{q} F(x) d x\right) .
\end{aligned}
$$

Theorem 1. If $\lambda<k$, then optimal control power of the manufacturer must satisfy $\beta \in(0.5,1)$.

Proof. $\beta \in(0.5,1)$, according to (21); if

$$
\frac{1}{2} \leq \beta=\frac{1}{2}+\frac{\lambda}{2 k}\left(F\left(q_{1}\right)-\frac{1}{q_{1}} \int_{0}^{q} F(x) d x\right) \leq 1,
$$

then

$$
\begin{gathered}
\Longleftrightarrow 0 \leq \frac{\lambda}{2 k}\left(F\left(q_{1}\right)-\frac{1}{q_{1}} \int_{0}^{q} F(x) d x\right) \leq \frac{1}{2} \\
\Longleftrightarrow 0 \leq \frac{\lambda}{k}\left(F\left(q_{1}\right)-\frac{1}{q_{1}} \int_{0}^{q} F(x) d x\right) \leq 1 \\
\because F\left(q_{1}\right)-\frac{1}{q_{1}} \int_{0}^{q} F(x) d x \\
\quad=\frac{1}{q_{1}} \int_{0}^{q_{1}} F\left(q_{1}\right) d x-\frac{1}{q_{1}} \int_{0}^{q} F(x) d x \\
\quad=\frac{1}{q_{1}} \int_{0}^{q_{1}}\left(F\left(q_{1}\right)-F(x)\right) d x \geq 0
\end{gathered}
$$

must be satisfied, and

$$
\because F\left(q_{1}\right)-\frac{1}{q_{1}} \int_{0}^{q} F(x) d x<F\left(q_{1}\right)<1 .
$$

Hence, if $\lambda / k<1,0 \leq(\lambda / k)\left(F\left(q_{1}\right)-\left(1 / q_{1}\right) \int_{0}^{q} F(x) d x\right) \leq$ 1 , then $\beta \in(0.5,1)$. Therefore, Theorem 1 is right.

4.2. Model 2: Supply Chain Dominated by Retailer with Decentralized Decision. In this case, it is assumed that the retailer's control power $t>0.5$ allows the retailer to decide the wholesale price and control power $t$, while the production quantity is determined by the manufacturer. Then, the manufacturer and retailer will present a typical Stackelberg game, in which the retailer is the leader and the manufacturer is follower.

(1) Manufacturer Makes the Decision. First of all, in manufacturer decision-making, the manufacturer determines the optimal $q$ in order to maximize expected profit:

$$
\pi_{m 2}\left(q_{2}\right)=\left(w_{2}-c_{s}\right) q_{2}-\lambda \beta I\left(q_{2}\right)-\frac{k}{2} \beta^{2} q_{2} .
$$

Taking the first derivative of $q_{2}$ with respect to $\pi_{m 2}\left(q_{2}\right)$, the following equation can be obtained:

$$
\frac{\partial \pi_{m 2}\left(q_{2}\right)}{\partial q_{2}}=\left(w_{2}-c_{s}\right)-\lambda \beta F\left(q_{2}\right)-\frac{k}{2} \beta^{2} .
$$

According to the second derivative, $\partial^{2} \pi_{m 2}\left(q_{2}\right) / \partial q_{2}{ }^{2}=$ $-\lambda \beta f\left(q_{2}\right)<0$.

Thus, when $\pi_{m 2}\left(q_{2}\right)$ achieves its optimal capacity, $q_{2}$ should satisfy $\left(w_{2}-c_{s}\right)-\lambda \beta F\left(q_{2}\right)-(k / 2) \beta^{2}=0$. So, $F\left(q_{2}\right)=$ $\left(w_{2}-c_{s}-(k / 2) \beta^{2}\right) / \lambda \beta$; namely,

$$
q_{2}{ }^{*}=F^{-1}\left(\frac{w_{2}-c_{s}-(k / 2) \beta^{2}}{\lambda \beta}\right) .
$$

At this point, the retailer's wholesale price is

$$
w_{2}=c_{s}+\lambda \beta F\left(q_{2}{ }^{*}\right)+\frac{k}{2} \beta^{2} .
$$

(2) Retailer Makes the Decision. Here, in retailer decisionmaking, the retailer determines the optimal wholesale price $w_{2}$ and control power $1-\beta$.

The retailer's profit function is

$$
\begin{aligned}
\pi_{r 2}\left(q_{2}, w_{2}\left(q_{2}\right)\right)= & {[p+g-\lambda(1-\beta)] S\left(q_{2}\right) } \\
& -\left(c_{r}+w_{2}-\lambda(1-\beta)\right) q_{2}-g \mu \\
& -\frac{k}{2}(1-\beta)^{2} q_{2} .
\end{aligned}
$$

Let $1-\beta=t$; then $\pi_{r 2}\left(q_{2}, w_{2}\left(q_{2}\right)\right)=[p+g-\lambda t] S\left(q_{2}\right)-$ $\left(c_{r}+w_{2}-\lambda t\right) q_{2}-g \mu-(k / 2) t^{2} q_{2}$.

Similarly, if the stochastic demand function $D$ has the characteristics of IGFR, then $\pi_{r 2}\left(q_{2}, w_{2}\left(q_{2}\right)\right)$ will strictly increase in $q_{2}$ (proof in Appendix B).

Thus, when $\partial \pi_{r 2}\left(q_{2}, w_{2}\left(q_{2}\right)\right) / \partial q_{2}=[p+g-\lambda t] \bar{F}\left(q_{2}\right)-$ $\left(c_{r}+w_{2}-\lambda t\right)-(k / 2) t^{2}-\left(\partial w_{2} / \partial q_{2}\right) q_{2}=0$, the corresponding profit function $\pi_{r 2}\left(q_{2}, w_{2}\left(q_{2}\right)\right)$ will achieve the optimal supply chain. By the solving process of Appendix C, $q_{2}{ }^{*}$ must satisfy the following equation:

$$
\begin{aligned}
& F\left(q_{2}{ }^{*}\right) \\
& =\frac{p+g-\lambda \beta f(q) q_{2}-\lambda \beta-c_{r}-(k / 2) t^{2}-c_{s}-(k / 2) \beta^{2}}{p+g-\lambda+\lambda \beta} .
\end{aligned}
$$

Therefore, $w_{2}=c_{s}+\lambda \beta F\left(q_{2}{ }^{*}\right)+(k / 2) \beta^{2}$. 
The retailer's optimal control power $t$ will be solved as follows.

The profit function of the retailer is

$$
\begin{aligned}
\pi_{r 2}\left(q_{2}, w\left(q_{2}\right)\right) \\
=[p+g-\lambda t] S\left(q_{2}\right)-\left(c_{r}+w_{2}-\lambda t\right) q_{2}-g \mu \\
\quad-\frac{k}{2} t^{2} q_{2} \\
=[p+g-\lambda t] S\left(q_{2}\right)-c_{r} q_{2} \\
\quad-\left(c_{s}+\lambda(1-t) F\left(q_{2}{ }^{*}\right)+\frac{k}{2}(1-t)^{2}\right)+\lambda t q_{2} \\
\quad-g \mu-\frac{k}{2} t^{2} q_{2} .
\end{aligned}
$$

So, $\partial \pi_{r 2}\left(q_{2}, w\left(q_{2}\right)\right) / \partial t=-\lambda S\left(q_{2}\right)+\lambda F\left(q_{2}\right) q_{2}+k(1-t) q_{2}+$ $\lambda q_{2}-k t q_{2}$.

Take the second derivative of $t$ with respect to $\pi_{r 2}\left(q_{2}\right)$; the following equation can be derived: $\partial^{2} \pi_{r 2}\left(q_{2}, w\left(q_{2}\right)\right) / \partial t^{2}=$ $-2 k q_{2}<0$. Obviously, the retailer's profit achieves the optimum when $\partial \pi_{r 2}\left(q_{2}, w\left(q_{2}\right)\right) / \partial t=-\lambda S\left(q_{2}\right)+\lambda F\left(q_{2}\right) q_{2}+$ $k(1-t) q_{2}+\lambda q_{2}-k t q_{2}=0$. Then, $-\lambda S\left(q_{2}\right)+\lambda F\left(q_{2}\right) q_{2}+k q_{2}+$ $\lambda q_{2}-2 k t q_{2}=0$

$$
\begin{aligned}
t & =\frac{-\lambda S\left(q_{2}\right)+\lambda F\left(q_{2}\right) q_{2}+k q_{2}+\lambda q_{2}}{2 k q_{2}} \\
& =\frac{1}{2}+\frac{\lambda\left(F\left(q_{2}\right) q_{2}-S\left(q_{2}\right)+q_{2}\right)}{2 k q_{2}} \\
& =\frac{1}{2}+\frac{\lambda\left(F\left(q_{2}\right) q_{2}+\int_{0}^{q_{2}} F(x) d x\right)}{2 k q_{2}} .
\end{aligned}
$$

Theorem 2. The optimal control power must be greater than 0.5 when the retailer dominates the supply chain. Moreover, $t=$ $\min \left(1 / 2+\lambda\left(F\left(q_{2}\right) q_{2}+\int_{0}^{q_{2}} F(x) d x\right) / 2 k q_{2}, 1\right)$.

Proof. From (32), the following equation can be obtained:

$$
\begin{aligned}
& \because F\left(q_{2}\right) q_{2}>0, \int_{0}^{q_{2}} F(x) d x>0 \\
& \therefore \frac{\lambda\left(F\left(q_{2}\right) q_{2}+\int_{0}^{q_{2}} F(x) d x\right)}{2 k q_{2}}>0 \\
& \therefore t>\frac{1}{2} .
\end{aligned}
$$

Besides, $t$ cannot be greater than 1 ; hence,

$$
t=\min \left(\frac{1}{2}+\frac{\lambda\left(F\left(q_{2}\right) q_{2}+\int_{0}^{q_{2}} F(x) d x\right)}{2 k q_{2}}, 1\right) .
$$

4.3. Model 3: Supply Chain with Centralized Decision. In this model, the retailer and manufacturer form a unified organization, by which the wholesale price and quantity of goods are decided. In the case of centralized decisionmaking, retailers and manufacturers make decisions together. The profit function of the retailer is $\pi_{r_{3}}\left(q_{3}\right)=p S\left(q_{3}\right)-$ $g L\left(q_{3}\right)-\left(c_{r}+w_{3}\right) q_{3}+\lambda I\left(q_{3}\right)$.

The manufacturer's profit function is $\pi_{m_{3}}(q)=\left(w_{3}-\right.$ $\left.c_{s}\right) q_{3}-\lambda I\left(q_{3}\right)$.

The profit function of overall supply chain with centralized decisions is $\pi_{3}$ :

$$
\begin{aligned}
\pi_{3}\left(q_{3}\right)= & \pi_{r 3}\left(q_{3}\right)+\pi_{m 3}\left(q_{3}\right) \\
= & p S\left(q_{3}\right)-g L\left(q_{3}\right)-\left(c_{r}+w_{3}\right) q_{3}+\lambda I\left(q_{3}\right) \\
& +\left(w_{3}-c_{s}\right) q_{3}-\lambda I\left(q_{3}\right) \\
= & p\left(q_{3}-\int_{0}^{q_{3}} F(x) d x\right) \\
& -g\left(\mu-q_{3}+\int_{0}^{q_{3}} F(x) d x\right)-\left(c_{r}+c_{s}\right) g_{3} .
\end{aligned}
$$

Take the first and second derivatives of $q_{3}$ with respect to (35); the following equation can be obtained:

$$
\begin{aligned}
\frac{\partial \pi_{3}}{\partial q_{3}} & =p\left(1-F\left(q_{3}\right)\right)-g\left(-1+F\left(q_{3}\right)\right)-\left(c_{r}+c_{s}\right) \\
& =p+g-(p+g) F\left(q_{3}\right)-\left(c_{r}+c_{s}\right) .
\end{aligned}
$$

Therefore, $\partial^{2} \pi_{3} / \partial q_{3}{ }^{2}=-(p+g) f\left(q_{3}\right)$. Obviously, $\partial^{2} \pi_{3} / \partial q_{3}{ }^{2} \leq 0$, so (35) is a concave function.

From the first derivative, the optimal order quantity is

$$
q_{3}^{*}=F^{-1}\left(\frac{p+g-c_{r}-c_{s}}{p+g}\right) \text {. }
$$

By the retailer's profit function, the upper limit of the wholesale price must satisfy

$$
\begin{aligned}
\pi_{r 3}(q) & =p S\left(q_{3}\right)-g L\left(q_{3}\right)-\left(c_{r}+w_{3}\right) q_{3}+\lambda I\left(q_{3}\right) \\
& \geq 0 \\
\therefore 0 & \leq w_{3} \leq w_{3}^{\max } \\
& =\frac{p S\left(q_{3}\right)-g L\left(q_{3}\right)-c_{r} q_{3}+\lambda I\left(q_{3}\right)}{q_{3}} .
\end{aligned}
$$

4.4. Model 4: Supply Chain Dominated by Both Manufacturer and Retailer. In this model, the retailer and manufacturer dominate the supply chain together (i.e., $\beta=t=1 / 2$ ). Due to the equal control power, it will be hard to achieve a consistent quantity and thus realize the supply chain coordination if they all optimize their own order quantity. Therefore, it is necessary to introduce the NASH negotiation model in order to satisfy both members $[28,29]$. 
The profit function of the retailer is

$$
\begin{aligned}
\pi_{r 4}\left(q_{4}\right)= & p S\left(q_{4}\right)-g L\left(q_{4}\right)-\left(c_{r}+w_{4}\right) q_{4} \\
& +\lambda \beta I\left(q_{4}\right)-\frac{k}{2}(1-\beta)^{2} q_{4} \\
= & p S\left(q_{4}\right)-g L\left(q_{4}\right)-\left(c_{r}+w_{4}\right) q_{4} \\
& +\frac{1}{2} \lambda I\left(q_{4}\right)-\frac{k}{8} q_{4} .
\end{aligned}
$$

The profit function of the manufacturer is

$$
\begin{aligned}
\pi_{m 4}\left(q_{4}\right) & =\left(w_{4}-c_{s}\right) q_{4}-\lambda \beta I\left(q_{4}\right)-\frac{k}{2} \beta^{2} q_{4} \\
& =\left(w_{4}-c_{s}\right) q_{4}-\frac{1}{2} \lambda I\left(q_{4}\right)-\frac{k}{8} q_{4} .
\end{aligned}
$$

Then, by introducing the NASH negotiation model, the following model can be obtained:

$\max \pi$

$$
=\left(\pi_{m 4}\left(q_{4}\right)-\pi_{m 4}^{\min }\right)\left(\pi_{r 4}\left(q_{4}\right)-\pi_{r 4}^{\min }\right)
$$

subject to $\pi_{m 4}\left(q_{4}\right) \geq \pi_{m 4} \min$

$$
\begin{aligned}
& \pi_{r 4}\left(q_{4}\right) \geq \pi_{r 4} \min \\
& \pi_{m 4}\left(q_{4}\right)+\pi_{r 4}\left(q_{4}\right) \leq \pi_{3} .
\end{aligned}
$$

The manufacturer and retailer relate with cooperation, so when both sides do not cooperate, the smallest earnings on both sides will be zero.

Therefore, the above model can be changed to

$$
\begin{aligned}
\max & \pi=\pi_{m 4}\left(q_{4}\right) \pi_{r 4}\left(q_{4}\right) \\
\text { subject to } & \pi_{m 4}\left(q_{4}\right) \geq 0 \\
& \pi_{r 4}\left(q_{4}\right) \geq 0 \\
& \pi_{m 4}\left(q_{4}\right)+\pi_{r 4}\left(q_{4}\right) \leq \pi_{3} .
\end{aligned}
$$

The optimal solution must be obtained when the above three formulas achieve an equation, so the original formula is equivalent to

$$
\begin{aligned}
\max & \pi=\pi_{m 4}\left(q_{4}\right) \pi_{r 4}\left(q_{4}\right) \\
\text { subject to } & \pi_{m 4}\left(q_{4}\right)+\pi_{r 4}\left(q_{4}\right) \leq \pi_{3} .
\end{aligned}
$$

The condition under which the above formula achieves the optimal value is $\pi_{m 4}\left(q_{4}\right)=\pi_{r 4}\left(q_{4}\right)$; then,

$$
\begin{aligned}
p S & \left(q_{4}\right)-g L\left(q_{4}\right)-\left(c_{r}+w_{4}\right) q_{4}+\frac{1}{2} \lambda I\left(q_{4}\right)-\frac{k}{8} q_{4} \\
& =\left(w_{4}-c_{s}\right) q_{4}-\frac{1}{2} \lambda I\left(q_{4}\right)-\frac{k}{8} q_{4} .
\end{aligned}
$$

It can be simplified as follows: $\left(p+g+c_{s}-c_{r}-2 w_{4}-k / 4\right)-$ $(p+g-\lambda) F\left(q_{4}\right)=0$.
So, $q_{4}{ }^{*}=F^{-1}\left(\left(p+g+c_{s}-c_{r}-2 w_{4}-k / 4\right) /(p+g-\lambda)\right)$. Consider the following:

$$
w_{4}=\frac{p+g+c_{s}-c_{r}-k / 4-(p+g-\lambda) F\left(q_{4}^{*}\right)}{2} .
$$

Take the first derivative of $q_{4}$ with respect to $w_{4}$; then $\partial w_{4} / \partial q_{4}=-(p+g-\lambda) f\left(q_{4}\right) / 2$.

Taking the first derivative of $q_{4}$ with respect to $\pi_{m 4}\left(q_{4}\right)$ and substituting (45) into it, the following can be obtained:

$$
\begin{aligned}
\frac{\partial \pi_{m 4}\left(q_{4}\right)}{\partial q_{4}} & \\
= & -\frac{(p+g-\lambda) q_{4} f\left(q_{4}\right)}{2}+\left(w_{4}-c_{s}\right)-\frac{1}{2} \lambda F\left(q_{4}\right) \\
& -\frac{k}{8} \\
= & -\frac{(p+g-\lambda) q_{4} f\left(q_{4}\right)}{2} \\
& +\frac{p+g+c_{s}-c_{r}-k / 4-(p+g-\lambda) F\left(q_{4}\right)}{2} \\
& -c_{s}-\frac{1}{2} \lambda F\left(q_{4}\right)-\frac{k}{8} \\
= & \frac{(p+g) F\left(q_{4}\right)}{2}-\frac{(p+g-\lambda) q_{4} f\left(q_{4}\right)}{2} \\
& +\frac{p+g-c_{s}-c_{r}-k / 4}{2}-\frac{k}{8} .
\end{aligned}
$$

$\pi_{m 4}\left(q_{4}\right)$ is proven to be strictly increasing in $q_{4}$, and the proof is seen in Appendix D.

Let

$$
\frac{\partial \pi_{m 4}\left(q_{4}\right)}{\partial q_{4}}=0
$$

so

$$
\begin{gathered}
\frac{-(p+g) F\left(q_{4}\right)}{2}-\frac{(p+g-\lambda) q_{4} f\left(q_{4}\right)}{2} \\
+\frac{p+g-c_{s}-c_{r}-k / 4}{2}-\frac{k}{8}=0 .
\end{gathered}
$$

Then

$$
\begin{aligned}
& F\left(q_{4}\right) \\
& \qquad=\frac{p+g-c_{s}-c_{r}-k / 2-(p+g-\lambda) q_{4} f\left(q_{4}\right)}{p+g} .
\end{aligned}
$$

So,

$q_{4}^{*}$

$=F^{-1}\left(\frac{p+g-c_{s}-c_{r}-k / 2-(p+g-\lambda) q_{4} f\left(q_{4}\right)}{p+g}\right)$. 


\section{Comparisons among Four Models}

\subsection{Comparison of $q$}

Theorem 3. If $p+g>3 \lambda$ and $q f(q) \geq \lambda /(p+g-2 \lambda)$, then $q_{2}^{*}>q_{1}^{*}$.

The proof is seen in Appendix E.

Theorem 3 shows that the order quantity when the retailer dominates the supply chain can be more than that of the supply chain dominated by the manufacturer in certain conditions. That illustrates why the retail channels such as Wal-Mart will exist: order quantity will be more when WalMart dominates the supply chain.

Theorem 4. If $\lambda \beta-k / 4<\lambda \beta q f(q)$, then $q_{3}{ }^{*}>q_{2}{ }^{*}$.

The proof is seen in Appendix F.

Theorem 4 indicates that, when meeting certain conditions, the order quantity with centralized decision-making will be greater than that of the supply chain dominated by the retailer. Besides, it also illustrates that the order quantity with centralized decision-making may be not the largest in all modes of decision-making and less than the order quantity in the retailer dominant mode.

Theorem 5. If $k / 4>\lambda \operatorname{tq} f(q)$, then $q_{1}{ }^{*}>q_{4}{ }^{*}$.

The proof is seen in Appendix G.

Theorem 5 shows that, in some conditions, the order quantity when the manufacturer dominates the supply chain will be greater than that when the manufacturer and the retailer have equal control power. It also illustrates that when the manufacturer and retailer control the supply chain together, the order quantity may be the smallest.

According to Theorems 3, 4, and 5, if $p+g>3 \lambda, q f(q) \geq$ $\lambda /(p+g-2 \lambda)$, and $k / 4>\max (\lambda t q f(q), \lambda \beta-\lambda \beta q f(q))$, then $q_{4}{ }^{*}<q_{1}{ }^{*}<q_{2}{ }^{*}<q_{3}{ }^{*}$.

\subsection{Comparison of $w$}

Theorem 6. If $q_{2}{ }^{*}>q_{1}{ }^{*}$ and $(t-\beta) /(t+\beta) \leq f\left(q_{2}{ }^{*}\right) q_{2}{ }^{*}$, then $w_{1}\left(q_{1}{ }^{*}\right) \geq w_{2}\left(q_{2}{ }^{*}\right)$.

The proof is seen in Appendix H.

Theorem 6 illustrates that, in certain parameter conditions, the order quantity in the supply chain dominated by the retailer will be greater than that when the manufacturer leads the supply chain. Moreover, the wholesale price will be less than that when the manufacturer dominates the supply chain. At the same time, it shows that supply chain dominated by the retailer can better meet the demand of the market, and this is the reason why Wal-Mart and other global retail giants occupy dominant positions in the supply chain.

\subsection{Comparison of $\beta$}

Theorem 7. If $q_{2}{ }^{*}>q_{1}{ }^{*}$, then manufacturer's optimal control power $\beta$ in Model 1 will be smaller than the retailer's control powert in Model 2.

The proof is seen in Appendix I.
Theorem 7 illustrates that when meeting the specific circumstances, such as $q_{2}{ }^{*}>q_{1}{ }^{*}$, control power of the supply chain led by the manufacturer will be less than that of the supply chain led by the retailer.

Table 1 shows the comparative results of decision parameters under the four models.

\section{Main Conclusions and Management Insights}

6.1. Main Conclusions. This paper introduces the parameters of supply chain control power into existing supply chain coordination models and explores the impact of control power on the profits of the manufacturer, the retailer, and the overall supply chain under four cooperation models, including decentralized decision-making dominated by the manufacturer, the decentralized decision-making dominated by the retailer, centralized decision-making, and Nash negotiation decision-making. Some significant conclusions are obtained. According to the comparison and discussion of the analysis results of four modes in Sections 5 and 6, the following conclusions can be obtained.

6.1.1. Intuitional Conclusions. Firstly, supply chain control power does affect the profit of the whole supply chain, generally speaking, $\pi_{s 3}{ }^{*}>\pi_{s 2}{ }^{*}>\pi_{s 1}{ }^{*}>\pi_{s 4}{ }^{*}$, which shows that the profit of the whole supply chain with centralized decision-making is best compared to the other three modes of control.

Secondly, in the supply chain system with decentralized decision-making, the owner of the supply chain will gain greater benefits. This shows that, in the collaboration of supply chains, control power is an important parameter, as the more the control power there is, the greater profits one party will have over another one.

6.1.2. Unexpected Conclusions. Firstly, from the view of optimal supply chain profits, the profit with decentralized decision-making is superior to that when the retailer and manufacturer have equal control power, which also indirectly proves an interesting phenomenon. The implication is that the mode of equal control power is not a common pattern, while the supply chain cooperation controlled by one dominant party is more common in the current practice.

Secondly, in the supply chain system with decentralized decision-making, the greater control power a member of the supply chain has, the more responsibilities and risks it should take, so both sides do not blindly increase their control in order to maximize their profits; thus there exists an optimal control power: $\beta$ and $t$, for the manufacturer-dominated supply chain and retailer-dominated supply chain, respectively. Consider the following:

$$
\begin{aligned}
& \beta=\frac{1}{2}+\frac{\lambda}{2 k}\left(F\left(q_{1}\right)-\frac{1}{q_{1}} \int_{0}^{q} F(x) d x\right), \\
& t=\min \left(\frac{1}{2}+\frac{\lambda\left(F\left(q_{2}\right)-\left(1 / q_{2}\right) \int_{0}^{q} F(x) d x\right)}{2 k}, 1\right) .
\end{aligned}
$$




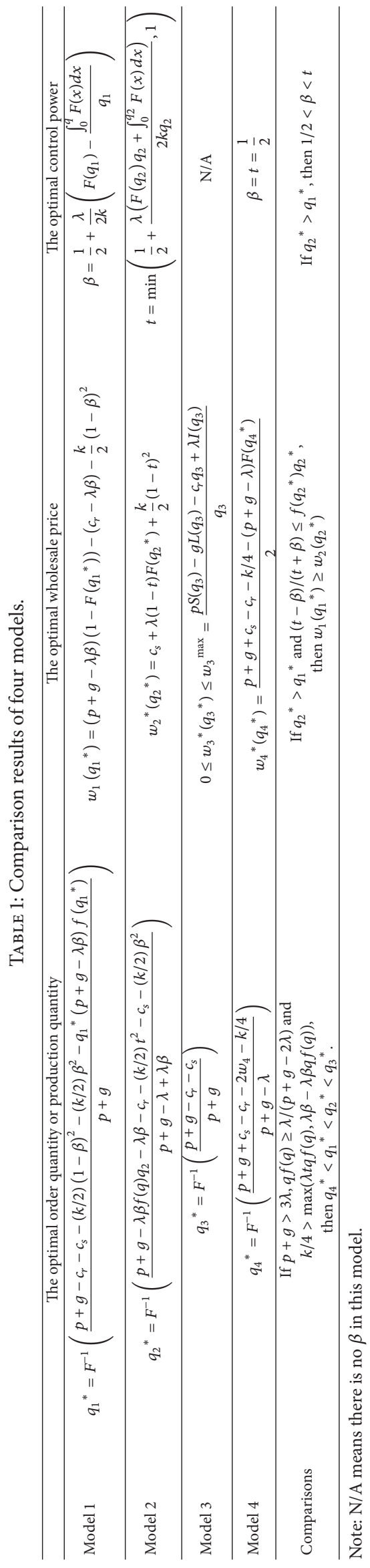


Thirdly, when some certain conditions are satisfied, order quantity will increase, the wholesale price will decrease, and the profits will be greater than the supply chain dominated by the manufacturer with the supply chain control power transferring from the manufacturer to the retailer. This also explains why the retailer-dominated supply chain (such as a Wal-Mart-dominated supply chain) has increasingly become a common form of supply chain collaboration in the fierce market competition.

Fourthly, when meeting certain conditions, order quantity in a manufacturer-dominant supply chain will be greater than that when the manufacturer and retailer dominate the supply chain together. This also illustrates that when they have equal control power, the order quantity may be a kind of minimum order, and the profits of the supply chain are the lowest ones compared with the other three modes of cooperation. On the whole, it is not a stable and effective cooperation pattern when the manufacturer and retailer own equal control power. Instead, supply chain partnership led by a member of the group is a more common and stable cooperation.

6.2. Implications for Researchers. This study introduces supply chain cooperation based on the control mode, researches four modes of coordination (centralized decision-making, supply chain dominated by the manufacturer, supply chain dominated by the retailer, and supply chain dominated by both the manufacturer and retailer), and explores the effect of control power on the result of their decision. For researchers, there are mainly the following two enlightenments. On one hand, this paper introduces the endogenous variable of control power and builds the supply chain cooperation based on the control mode. This kind of modeling method can provide a reference for subsequent researchers. On the other hand, our research indicates that when the manufacturer and retailer both dominate the supply chain, their profit is greater than that of the other three cases. But "the bigger, the better" does not always apply. It is different from a previous conclusion in Demirkan and Cheng [6]. The optimal control power in different modes of control found in this paper also enriches the achievements of previous scholars.

6.3. Implications for Managers. From the practical point of view, this paper can also provide reference for retailers when they make decisions on control power in the following three aspects.

(1) From the view of practice, the allocation of supply chain control power in different members is of great significance to the sustainability of the supply chain cooperation. Moreover, the rational design of control power can also help to ensure the stable operation of supply chains in the construction of a new supply chain. Therefore, managers need to clearly understand the role of control power in the supply chain cooperation.

(2) For manufacturers and retailers, it is beneficial to gain the control power of the supply chain; however "the bigger, the better" does not always apply. When making decisions, they should especially consider the influence of two parameters (the coefficient of subsidies manufacturers provide to retailers and the cost coefficient of control power) on their profits.

(3) When retailers and manufacturers have equal control power (i.e., Model 4), the gross profit of supply chain is the least, and the order quantity is the smallest. Therefore, when both manufacturers and retailers are equal in the fight for control power, they should abandon this kind of cooperation model. Moreover, they can take the cooperation pattern of the Stackelberg game and design a more reasonable mode of profit sharing in order to get more profits.

(4) When meeting certain conditions, order quantity will increase, and the wholesale price will decrease with supply chain control power transferring from manufacturers to retailers. By this time, the gross profit of supply chains dominated by retailers will be greater than the gross profit of supply chains dominated by manufacturers. As a result, retailers should lead supply chains.

6.4. Research Limitations and Directions for Future Research. Although this paper provides some theoretical basis for the supply chain contract coordination research based on control power, there are also some deficiencies. For example, it is assumed that when the manufacturer and retailer use centralized decision-making (i.e., Model 3), there is no risk cost; in fact, risk exists in every decision model. For future research, more work could be done to reduce the supply chain risk level based on the given risk cost, as well as the influence of risk cost on the optimal control power. Numerical verification for the demand will be conducted with normal distribution in future research. Moreover, the analysis of the factors influencing the control power is not comprehensive enough in this paper. For example, the gross profit in Model 4 is considered the least of the four kinds of models. However, with a more reasonable profit-sharing mechanism designed, a manufacturer and retailer with equal control power can gain more profit and increase their cooperation performance.

\section{Appendices}

\section{A. Solving Process of $q_{1}{ }^{*}$}

Proof. Let $Q_{1}=\min \left(0, q_{1} f\left(q_{1}\right) / \bar{F}\left(q_{1}\right)=1\right)$.

(1) When $q_{1} \in\left(0, Q_{1}\right), H\left(q_{1}\right)>0, \partial^{2} \pi_{m 1}\left(q_{1}\right) / \partial q_{1}{ }^{2}<0$, which indicates that $\pi_{m 1}\left(q_{1}\right)$ is a strictly concave function in this range. Then, when $\pi_{m 1}\left(q_{1}\right)$ achieves the optimum $q_{1}{ }^{*}$ should satisfy $q_{1}{ }^{*} \in\left(0, Q_{1}\right)$.

(2) When $q_{1} \in\left[Q_{1},+\infty\right)$, the following can be obtained:

$$
\begin{aligned}
\frac{\partial \pi_{m 1}\left(q_{1}\right)}{\partial q_{1}}= & (p+g-\lambda \beta) \bar{F}\left(q_{1}\right)\left(1-\frac{q_{1} f\left(q_{1}\right)}{\bar{F}\left(q_{1}\right)}\right) \\
& -\left(c_{r}-\lambda \beta\right)-\frac{k}{2}(1-\beta)^{2}-c_{s} \\
& -\lambda \beta F(q)-\frac{k}{2} \beta^{2} .
\end{aligned}
$$


$\left(1-q_{1} f\left(q_{1}\right) / \bar{F}\left(q_{1}\right)\right)<0$, so in this range, $\partial \pi_{m 1}\left(q_{1}\right) / \partial q_{1}<0$; then, $\pi_{m 1}\left(q_{1}\right)$ appears strictly decreasing in this range. And when it achieves the maximum in this range, $q_{1}=Q_{1}$.

Integrate the interval of $q_{1} \in\left(0, Q_{1}\right)$ and $q_{1} \in\left[Q_{1},+\infty\right)$; it can be obtained that when $\pi_{m 1}\left(q_{1}\right)$ achieves the maximum, $q_{1}{ }^{*}$ must satisfy $q_{1}{ }^{*} \in\left(0, Q_{1}\right)$. Then, let

$$
\begin{aligned}
\frac{\partial \pi_{m 1}\left(q_{1}\right)}{\partial q_{1}}= & (p+g-\lambda \beta) \bar{F}\left(q_{1}\right)\left(1-\frac{q_{1} f\left(q_{1}\right)}{\bar{F}\left(q_{1}\right)}\right) \\
& -\left(c_{r}-\lambda \beta\right)-\frac{k}{2}(1-\beta)^{2}-c_{s} \\
& -\lambda \beta F(q)-\frac{k}{2} \beta^{2}=0 .
\end{aligned}
$$

$$
\begin{aligned}
& p+g-c_{r}-\frac{k}{2}(1-\beta)^{2}-c_{s}-\frac{k}{2} \beta^{2}-q_{1}(p+g-\lambda \beta) f\left(q_{1}\right)=(p+g) F\left(q_{1}\right) \\
& F\left(q_{1}^{*}\right)=\frac{p+g-c_{r}-c_{s}-(k / 2)(1-\beta)^{2}-(k / 2) \beta^{2}-q_{1}{ }^{*}(p+g-\lambda \beta) f\left(q_{1}{ }^{*}\right)}{p+g} .
\end{aligned}
$$

\section{B. Proof of the Unimodality of $\pi_{r 2}\left(q_{2}, w_{2}\left(q_{2}\right)\right)$}

Proof. From (28) in Model 2 and $\pi_{r 2}\left(q_{2}, w_{2}\left(q_{2}\right)\right)$, the following equation can be obtained:

$$
\begin{aligned}
w_{2} & =c_{s}+\lambda \beta F\left(q_{2}{ }^{*}\right)+\frac{k}{2} \beta^{2} \\
\frac{\partial \pi_{r 2}\left(q_{2}, w_{2}\left(q_{2}\right)\right)}{\partial q_{2}}= & \left(p+g-c_{r}-w_{2}\right) \\
& -(p+g-\lambda t) F(q)-\frac{k}{2} t^{2} \\
& -\frac{\partial w_{2}}{\partial q_{2}} q_{2} .
\end{aligned}
$$

Substitute (B.1) into (B.2):

$$
\begin{aligned}
& \frac{\partial \pi_{r 2}\left(q_{2}, w_{2}\left(q_{2}\right)\right)}{\partial q_{2}} \\
& =\left(p+g-c_{r}-c_{s}-\lambda \beta F(q)-\frac{k}{2} \beta^{2}\right) \\
& \quad-(p+g-\lambda t) F(q)-\frac{k}{2} t^{2}-\lambda \beta q f(q) \\
& =(p+g) \bar{F}(q)-\lambda \beta F(q)+\lambda t F(q)-c-\frac{k}{2} \beta^{2} \\
& \quad-\frac{k}{2} t^{2}-\lambda \beta q f(q)
\end{aligned}
$$

The following equation can be obtained:

$$
\begin{aligned}
\frac{\partial \pi_{m 1}\left(q_{1}\right)}{\partial q_{1}}= & -(p+g) F\left(q_{1}\right)+p+g-c_{r} \\
& -\frac{k}{2}(1-\beta)^{2}-c_{s}-\frac{k}{2} \beta^{2} \\
& -q_{1}(p+g-\lambda \beta) f\left(q_{1}\right)=0 .
\end{aligned}
$$

Hence,

$$
\begin{aligned}
= & (p+g-\lambda(t-\beta)) \bar{F}(q)-\lambda \beta q f(q) \\
& +\lambda(t-\beta)-c-\frac{k}{2} \beta^{2}-\frac{k}{2} t^{2} \\
= & \lambda \beta \bar{F}(q)\left[\frac{p+g-\lambda(t-\beta)}{\lambda \beta}-\frac{q f(q)}{\bar{F}(q)}\right] \\
& +\lambda(t-\beta)-c-\frac{k}{2} \beta^{2}-\frac{k}{2} t^{2} .
\end{aligned}
$$

Take the second derivative of $q_{2}$ with respect to $\pi_{r 2}\left(q_{2}\right)$ :

$$
\begin{aligned}
\frac{\partial^{2} \pi_{r 2}\left(q_{2}, w_{2}\left(q_{2}\right)\right)}{\partial q_{2}{ }^{2}} \\
=\lambda \beta \bar{F}(q) H(q) \\
\quad-\lambda \beta f(q)\left[\frac{p+g-\lambda(t-\beta)}{\lambda \beta}-\frac{q f(q)}{\bar{F}(q)}\right] .
\end{aligned}
$$

In (B.4), $H(q)=q f(q) / \bar{F}(q)$ is called increasing generalized failure rate (IGFR) of the stochastic demand $D$. Namely, under the IGFR demand distribution, the general failure rate $H\left(q_{1}\right)$ is strictly increasing in $q$ if $F(q)<1$ [40]. Due to the demand distribution function that has the feature of IGFR, we can divide it into two cases.

(1) When $q_{2} \in\left(0, Q_{2}\right), H(q)>0, \partial^{2} \pi_{r 2}\left(q_{2}, w_{2}\left(q_{2}\right)\right) /$ $\partial q_{2}{ }^{2}<0$, which indicates that $\pi_{r 2}\left(q_{2}\right)$ is a strictly concave function in this range. Then, when $\pi_{r 2}\left(q_{2}\right)$ achieves the optimum $q_{2}{ }^{*}$ should satisfy $q_{2}{ }^{*} \in\left(0, Q_{2}\right)$. 
(2) When $q_{2} \in\left[Q_{2},+\infty\right)$, we can get from the first derivative that

$$
\begin{aligned}
& \frac{\partial \pi_{r 2}\left(q_{2}, w_{2}\left(q_{2}\right)\right)}{\partial q_{2}} \\
& =\lambda \beta \bar{F}(q)\left[\frac{p+g-\lambda(t-\beta)}{\lambda \beta}-\frac{q f(q)}{\bar{F}(q)}\right] \\
& \quad+\lambda(t-\beta)-c-\frac{k}{2} \beta^{2}-\frac{k}{2} t^{2} .
\end{aligned}
$$

Due to $(p+g-\lambda(t-\beta)) / \lambda \beta-q f(q) / \bar{F}(q)<0$, $\partial \pi_{r 2}\left(q_{2}, w_{2}\left(q_{2}\right)\right) / \partial q_{2}<0$, in this range, then, $\pi_{r 2}\left(q_{2}\right)$ appears strictly decreasing in this range. And when it achieves the maximum in this range, $q=Q_{2}{ }^{*}$.

Integrate the interval of $q_{2} \in\left(0, Q_{2}\right)$ and $q_{2} \in\left[Q_{2},+\infty\right)$; it can be obtained that when $\pi_{r 2}\left(q_{2}\right)$ achieves the maximum, $q_{2}{ }^{*}$ must satisfy $q_{2}{ }^{*} \in\left(0, Q_{2}\right)$.

\section{Solving Process of $q_{2}{ }^{*}$}

Proof. In Model 2, when profit of manufacturer achieves the optimum, its derivative of $q_{2}$ must be zero; namely,

$$
\frac{\partial \pi_{m 2}\left(q_{2}\right)}{\partial q_{2}}=\left(w_{2}-c_{s}\right)-\lambda \beta F\left(q_{2}\right)-\frac{k}{2} \beta^{2}=0 .
$$

Thus, $w_{2}=c_{s}+\lambda \beta F\left(q_{2}{ }^{*}\right)+(k / 2) \beta^{2}$, and $\partial w_{2} / \partial q_{2}=$ $\lambda \beta f\left(q_{2}\right)$; then substitute $\partial w_{2} / \partial q_{2}=\lambda \beta f\left(q_{2}\right)$ into $\partial \pi_{r 2}\left(q_{2}, w_{2}\left(q_{2}\right)\right) / \partial q_{2}=[p+g-\lambda t] \bar{F}\left(q_{2}\right)-\left(c_{r}+w_{2}-\right.$ $\lambda t)-(k / 2) t^{2}-\partial w_{2} / \partial q_{2}=0$, so (C.2) must be satisfied:

$$
\begin{aligned}
& {[p+g-\lambda t] \bar{F}\left(q_{2}\right)-\left(c_{r}+w_{2}-\lambda t\right)-\frac{k}{2} t^{2}-\lambda \beta f(q) q_{2}} \\
& \quad=0 \\
& \Longleftrightarrow[p+g-\lambda t] \bar{F}\left(q_{2}\right)-c_{r}+\lambda t-\frac{k}{2} t^{2}-\lambda \beta f(q) q_{2} \\
& \quad-c_{s}-\lambda \beta F\left(q_{2}\right)-\frac{k}{2} \beta^{2}=0 \\
& \Longleftrightarrow[p+g-\lambda t] \bar{F}\left(q_{2}\right)-\lambda \beta\left(1-\bar{F}\left(q_{2}\right)\right)-\lambda \beta f(q) q_{2} \\
& \quad-c_{r}+\lambda t-\frac{k}{2} t^{2}-c_{s}-\frac{k}{2} \beta^{2}=0 \\
& \therefore[p+g-\lambda t+\lambda \beta] \bar{F}\left(q_{2}\right)=\lambda \beta+\lambda \beta f(q) q_{2}+c_{r}-\lambda t \\
& \quad+\frac{k}{2} t^{2}+c_{s}+\frac{k}{2} \beta^{2} \\
& \therefore \bar{F}\left(q_{2}\right) \\
& \quad=\frac{\lambda \beta+\lambda \beta f(q) q_{2}+c_{r}-\lambda t+(k / 2) t^{2}+c_{s}+(k / 2) \beta^{2}}{[p+g-\lambda t+\lambda \beta]} .
\end{aligned}
$$

So,

$$
\begin{aligned}
F\left(q_{2}\right) & =1-\frac{\lambda \beta+\lambda \beta f(q) q_{2}+c_{r}-\lambda t+(k / 2) t^{2}+c_{s}+(k / 2) \beta^{2}}{p+g-\lambda t+\lambda \beta} \\
& =\frac{p+g-\lambda t+\lambda \beta-\lambda \beta-\lambda \beta f(q) q_{2}-c_{r}+\lambda t-(k / 2) t^{2}-c_{s}-(k / 2) \beta^{2}}{p+g-\lambda t+\lambda \beta} \\
& =\frac{p+g-\lambda \beta f(q) q_{2}-\lambda \beta-c_{r}-(k / 2) t^{2}-c_{s}-(k / 2) \beta^{2}}{p+g-\lambda t+\lambda \beta} .
\end{aligned}
$$

Hence, the optimal $q_{2}{ }^{*}$ must satisfy

So,

$F\left(q_{2}{ }^{*}\right)$

$$
\begin{aligned}
=\frac{p+g-\lambda \beta f(q) q_{2}-\lambda \beta-c_{r}-(k / 2) t^{2}-c_{s}-(k / 2) \beta^{2}}{p+g-\lambda+\lambda \beta} . & \text { (C.5) } \\
q_{2}{ }^{*} & =F^{-1}\left(\frac{p+g-\lambda \beta f(q) q_{2}-\lambda \beta-c_{r}-(k / 2) t^{2}-c_{s}-(k / 2) \beta^{2}}{p+g-\lambda+\lambda \beta}\right) \\
& =F^{-1}\left(\frac{p+g-\lambda \beta f\left(q_{2}{ }^{*}\right) q_{2}{ }^{*}-\lambda \beta-c_{r}-c_{s}-(k / 2) t^{2}-(k / 2) \beta^{2}}{p+g-\lambda t}\right), \\
w_{2} & =c_{s}+\lambda \beta F\left(q_{2}{ }^{*}\right)+\frac{k}{2} \beta^{2} .
\end{aligned}
$$




\section{Proof of the Unimodality of $\pi_{m 4}\left(q_{4}\right)$}

Proof. From Model 4, we can get

$$
\begin{aligned}
& \frac{\partial \pi_{m 4}\left(q_{4}\right)}{\partial q_{4}} \\
& =\frac{-(p+g) F\left(q_{4}\right)}{2}-\frac{(p+g-\lambda) q_{4} f\left(q_{4}\right)}{2} \\
& \quad+\frac{p+g-c_{s}-c_{r}-k / 4}{2}-\frac{k}{8} \\
& =\frac{1}{2}\left((p+g) \bar{F}(q)\left[1-\frac{q f(q)}{\bar{F}(q)}\right]-c_{s}-c_{r}-\frac{k}{2}\right) .
\end{aligned}
$$

Assume that $Q=\min \{q: q f(q) / F(q)=1\}$, and the demand function meets the feature of IGFR; then, 1 $q f(q) / F(q)$ will be strictly decreasing in the range from 0 to $Q$, and some values in that range will be positive. Meanwhile, $\bar{F}(q)=1-F(q)$ is positive in the range of $[0, Q]$; thus, when $q \in[0, Q], \partial \pi_{m 4}\left(q_{4}\right) / \partial q_{4} \geq 0$. Moreover, $\bar{F}(q)=1-F(q)$ is also positive in the range of $[Q,+\infty]$, so $1-q f(q) / F(q)$ will be strictly decreasing and there must exist some positive values in that range. Thus, $\partial \pi_{m 4}\left(q_{4}\right) / \partial q_{4}<0$ in the range of $[Q,+\infty]$, and $\pi_{m 4}\left(q_{4}\right)$ is a unimodal function.

\section{E. Proof of Theorem 3}

Proof. From $q_{1}{ }^{*}=F^{-1}\left(\left(p+g-c_{r}-c_{s}-(k / 2)(1-\beta)^{2}-\right.\right.$ $\left.\left.(k / 2) \beta^{2}-q_{1}{ }^{*}(p+g-\lambda \beta) f\left(q_{1}{ }^{*}\right)\right) /(p+g)\right)$ and $q_{2}{ }^{*}=F^{-1}((p+$ $\left.\left.g-\lambda \beta f(q) q_{2}-\lambda \beta-c_{r}-(k / 2) t^{2}-c_{s}-(k / 2) \beta^{2}\right) /(p+g-\lambda+\lambda \beta)\right)$, $q_{1}{ }^{*}$ increases as $H(q)=p+g-c_{r}-c_{s}-(k / 2)(1-\beta)^{2}-$ $(k / 2) \beta^{2}-q(p+g-\lambda \beta) f(q)$ increases. $q_{2}{ }^{*}$ increases as $G(q)=$ $p+g-\lambda \beta f(q) q-\lambda \beta-c_{r}-c_{s}-k t^{2}-k t-k / 2$ increases. Hence, compare $H(q)$ and $G(q)$; we can get

$$
\begin{aligned}
& H(q)-G(q)=p+g-c_{r}-c_{s}-\frac{k}{2}(1-\beta)^{2}-\frac{k}{2} \beta^{2} \\
& -q(p+g-\lambda \beta) f(q)-(p+g-\lambda \beta f(q) q-\lambda \beta \\
& \left.-c_{r}-c_{s}-k t^{2}-k t-\frac{k}{2}\right)=-(p+g) f(q) q \\
& +2 \lambda \beta f(q) q+\lambda \beta .
\end{aligned}
$$

If $H(q) \leq G(q)$, then (E.1) means $\lambda \beta \leq(p+g-2 \lambda) f(q) q$ should be satisfied. $\because \beta \leq 1$, so (E.1) means $(p+g-2 \lambda) f(q) q \geq$ $\lambda$ should be satisfied; that is, $q f(q) \geq \lambda /(p+g-2 \lambda)$ should be satisfied.

So if $q f(q) \geq \lambda /(p+g-2 \lambda)$, then $H(q) \leq G(q)$.

And when $q_{1}$ and $q_{2}$ achieve the optimum, $f(q) q /(1-$ $F(q)) \leq 1$.

So, if $f(q) q \leq 1-F(q) \leq 1$, then $p+g-2 \lambda>\lambda$ must be satisfied:

$$
p+g>3 \lambda
$$

Thus, contact (E.1) and (E.2), and we will obtain the following conclusion.

If $q f(q) \geq \lambda /(p+g-2 \lambda)$ and $p+g>3 \lambda$, then $H(q) \leq G(q)$, and then

$$
\begin{gathered}
\frac{p+g-c_{r}-c_{s}-(k / 2)(1-\beta)^{2}-(k / 2) \beta^{2}-q_{1}{ }^{*}(p+g-\lambda \beta) f\left(q_{1}{ }^{*}\right)}{p+g} \\
\leq \frac{p+g-\lambda \beta f(q) q_{2}-\lambda \beta-c_{r}-(k / 2) t^{2}-c_{s}-(k / 2) \beta^{2}}{p+g-\lambda+\lambda \beta} .
\end{gathered}
$$

$$
\begin{aligned}
& F^{-1}\left(\frac{p+g-c_{r}-c_{s}-(k / 2)(1-\beta)^{2}-(k / 2) \beta^{2}-q_{1}{ }^{*}(p+g-\lambda \beta) f\left(q_{1}{ }^{*}\right)}{p+g}\right) \\
& \quad \leq F^{-1}\left(\frac{p+g-\lambda \beta f(q) q_{2}-\lambda \beta-c_{r}-(k / 2) t^{2}-c_{s}-(k / 2) \beta^{2}}{p+g-\lambda+\lambda \beta}\right) .
\end{aligned}
$$

\section{F. Proof of Theorem 4}

Proof. From the results of Model 2 and Model 3, 


$$
\begin{aligned}
q_{2}{ }^{*} & =F^{-1}\left(\frac{p+g-\lambda \beta f(q) q_{2}-\lambda \beta-c_{r}-(k / 2) t^{2}-c_{s}-(k / 2) \beta^{2}}{p+g-\lambda+\lambda \beta}\right), \\
q_{3}{ }^{*} & =F^{-1}\left(\frac{p+g-c_{r}-c_{s}}{p+g}\right) .
\end{aligned}
$$

Let

$$
\begin{aligned}
& H(q) \\
& \quad=1-\frac{c_{r}+c_{s}+\lambda \beta q f(q)+(k / 2)\left(\beta^{2}+t^{2}\right)-\lambda \beta}{p+g-\lambda t}, \\
& G(q)=1-\frac{c_{r}+c_{s}}{p+g} ;
\end{aligned}
$$

then $q_{2}$ will increase with the increase of $H(q)$, and $q_{3}$ will increase with the increase of $G(q)$ :

$$
\begin{aligned}
G(q) & -H(q) \\
= & \frac{c_{r}+c_{s}+\lambda \beta q f(q)+(k / 2)\left(\beta^{2}+t^{2}\right)-\lambda \beta}{p+g-\lambda t} \\
& -\frac{c_{r}+c_{s}}{p+g},
\end{aligned}
$$

$$
\begin{gathered}
c_{r}+c_{s}+\lambda \beta q f(q)+\frac{k}{2}\left(\beta^{2}+t^{2}\right)-\lambda \beta \\
>c_{r}+c_{s}+\lambda \beta q f(q)+\frac{k}{4}-\lambda \beta, \\
\because \lambda \beta-\frac{k}{4}<\lambda \beta q f(q), \\
\therefore c_{r}+c_{s}+\lambda \beta q f(q)+\frac{k}{4}-\lambda \beta>c_{r}+c_{s}
\end{gathered}
$$$$
\text { also } \because p+g-\lambda t<p+g \text {, }
$$$$
\therefore G(q)>H(q)
$$$$
\therefore q_{3}{ }^{*}>q_{2}{ }^{*} \text {. }
$$

\section{G. Proof of Theorem 5}

Proof. From the results of Model 1 and Model 4,

$$
\begin{aligned}
q_{1}{ }^{*} & =F^{-1}\left(\frac{p+g-c_{r}-c_{s}-(k / 2)(1-\beta)^{2}-(k / 2) \beta^{2}-q_{1}{ }^{*}(p+g-\lambda \beta) f\left(q_{1}{ }^{*}\right)}{p+g}\right) \\
q_{4} & =F^{-1}\left(\frac{p+g-c_{s}-c_{r}-(k / 2)-(p+g-\lambda) q_{4} f\left(q_{4}\right)}{p+g}\right) .
\end{aligned}
$$

Let

$$
\begin{aligned}
H(q)= & p+g-c_{s}-c_{r}-\frac{k}{2} t^{2}-\frac{k}{2} \beta^{2} \\
& -(p+g-\lambda \beta) q f(q), \\
G(q)= & p+g-c_{s}-c_{r}-\frac{k}{2}-(p+g-\lambda) q f(q) .
\end{aligned}
$$

Then $q_{1}$ will increase with the increase of $H(q)$, and $q_{4}$ will increase with the increase of $G(q)$. Hence,

$$
\begin{array}{cc}
H(q)-G(q)=\frac{k}{2}+(p+g-\lambda) q f(q)-\frac{k}{2} t^{2} & \text { H. Proof of Theorem } 6 \\
-\frac{k}{2} \beta^{2}-(p+g-\lambda \beta) q f(q) & \begin{array}{c}
\text { Proof. From Model 2, consider the following. } \\
\text { Due to }
\end{array} \\
q_{2}{ }^{*}=F^{-1}\left(\frac{p+g-\lambda \beta f(q) q_{2}-\lambda \beta-c_{r}-(k / 2) t^{2}-c_{s}-(k / 2) \beta^{2}}{p+g-\lambda+\lambda \beta}\right),
\end{array}
$$

\section{H. Proof of Theorem 6}


then $F\left(q_{2}{ }^{*}\right)=\left(p+g-\lambda \beta f(q) q_{2}-\lambda \beta-c_{r}-(k / 2) t^{2}-c_{s}-\right.$ $\left.(k / 2) \beta^{2}\right) /(p+g-\lambda+\lambda \beta)$, and

$$
\begin{aligned}
\therefore F\left(q_{2}{ }^{*}\right)(p+g)= & \lambda t F\left(q_{2}{ }^{*}\right)+p+g \\
& -\lambda \beta f\left(q_{2}{ }^{*}\right) q_{2}{ }^{*}-\lambda \beta-c_{r} \\
& -\frac{k}{2} t^{2}-c_{s}-\frac{k}{2} \beta^{2} .
\end{aligned}
$$

From (12) in Model 1 and (28), in Model 2, the following equation can be obtained:

$$
\begin{aligned}
w_{1}\left(q_{1}{ }^{*}\right)= & (p+g-\lambda \beta)\left(1-F\left(q_{1}{ }^{*}\right)\right)-\left(c_{r}-\lambda \beta\right) \\
& -\frac{k}{2}(1-\beta)^{2},
\end{aligned}
$$

$w_{2}\left(q_{2}{ }^{*}\right)=c_{s}+\lambda \beta F\left(q_{2}{ }^{*}\right)+\frac{k}{2} \beta^{2}$.

So,

$$
\begin{aligned}
w_{1}\left(q_{1}{ }^{*}\right)-w_{2}\left(q_{2}{ }^{*}\right)= & (p+g-\lambda \beta)\left(1-F\left(q_{1}{ }^{*}\right)\right) \\
& -\left(c_{r}-\lambda \beta\right)-\frac{k}{2}(1-\beta)^{2} \\
& -\left(c_{s}+\lambda \beta F\left(q_{2}{ }^{*}\right)+\frac{k}{2} \beta^{2}\right) \\
= & (p+g-\lambda \beta) \\
& -(p+g-\lambda \beta) F\left(q_{1}{ }^{*}\right)-c_{r} \\
& +\lambda \beta-\frac{k}{2}(1-\beta)^{2}-c_{s} \\
& -\lambda F\left(q_{2}{ }^{*}\right)+\lambda t F\left(q_{2}{ }^{*}\right) \\
& -\frac{k}{2}(1-t)^{2} \\
= & p+g-(p+g-\lambda \beta) F\left(q_{1}{ }^{*}\right) \\
& -\lambda(1-t) F\left(q_{2}{ }^{*}\right)-c_{r} \\
& -\frac{k}{2}(1-\beta)^{2}-c_{s} \\
& -\frac{k}{2}(1-t)^{2} .
\end{aligned}
$$
then

Because $q_{1}{ }^{*} \leq q_{2}{ }^{*}$, substitute $F\left(q_{1}{ }^{*}\right) \leq F\left(q_{2}{ }^{*}\right)$ into (H.4);

$$
\begin{aligned}
w_{1}\left(q_{1}{ }^{*}\right)-w_{2}\left(q_{2}{ }^{*}\right) & \\
> & p+g-(p+g-\lambda \beta) F\left(q_{2}{ }^{*}\right) \\
& -\lambda(1-t) F\left(q_{2}{ }^{*}\right)-c_{r}-\frac{k}{2}(1-\beta)^{2}-c_{s} \\
& -\frac{k}{2}(1-t)^{2}
\end{aligned}
$$

$$
\begin{aligned}
w_{1}\left(q_{1}{ }^{*}\right) & -w_{2}\left(q_{2}{ }^{*}\right) \\
> & p+g-(p+g) F\left(q_{2}{ }^{*}\right) \\
& +(\lambda \beta-\lambda+\lambda t) F\left(q_{2}{ }^{*}\right)-c_{r}-\frac{k}{2}(1-\beta)^{2}-c_{s} \\
& -\frac{k}{2}(1-t)^{2}
\end{aligned}
$$

$\because t>\beta$

$\therefore t+\beta>1$,

$\therefore \lambda \beta-\lambda+\lambda t>0$

$\therefore w_{1}\left(q_{1}^{*}\right)-w_{2}\left(q_{2}^{*}\right)$

$>p+g-(p+g) F\left(q_{2}^{*}\right)-c_{r}-\frac{k}{2}(1-\beta)^{2}-c_{s}$

$$
-\frac{k}{2}(1-t)^{2}
$$

Substitute (H.2) into (H.6); we can get

$$
\begin{aligned}
& w_{1}\left(q_{1}{ }^{*}\right)-w_{2}\left(q_{2}{ }^{*}\right)>p+g-(p+g) F\left(q_{2}{ }^{*}\right)-c_{r} \\
& -\frac{k}{2}(1-\beta)^{2}-c_{s}-\frac{k}{2}(1-t)^{2}=p+g \\
& -\left(\lambda t F\left(q_{2}{ }^{*}\right)+p+g-\lambda \beta f\left(q_{2}{ }^{*}\right) q_{2}{ }^{*}-\lambda \beta-c_{r}\right. \\
& \left.-c_{s}-\frac{k}{2} t^{2}-\frac{k}{2} \beta^{2}\right)-c_{r}-\frac{k}{2}(1-\beta)^{2}-c_{s}-\frac{k}{2}(1 \\
& -t)^{2}=-\lambda t F\left(q_{2}{ }^{*}\right)+\lambda \beta f\left(q_{2}{ }^{*}\right) q_{2}{ }^{*}+\lambda \beta+\frac{k}{2} t^{2} \\
& -\frac{k}{2} \beta^{2}-\frac{k}{2}(1-\beta)^{2}-\frac{k}{2}(1-t)^{2} \\
& \because 1>t>\beta>0.5,
\end{aligned}
$$

$\therefore-\lambda t F\left(q_{2}{ }^{*}\right)+\lambda \beta f\left(q_{2}{ }^{*}\right) q_{2}{ }^{*}+\lambda \beta+\frac{k}{2} t^{2}-\frac{k}{2} \beta^{2}$

$$
\begin{aligned}
& -\frac{k}{2}(1-\beta)^{2}-\frac{k}{2}(1-t)^{2}>-\lambda t F\left(q_{2}{ }^{*}\right) \\
& +\lambda \beta f\left(q_{2}{ }^{*}\right) q_{2}{ }^{*}+\lambda \beta \\
\therefore & w_{1}\left(q_{1}{ }^{*}\right)-w_{2}\left(q_{2}{ }^{*}\right)>-\lambda t F\left(q_{2}{ }^{*}\right)+\lambda \beta f\left(q_{2}{ }^{*}\right) \\
& \cdot q_{2}{ }^{*}+\lambda \beta .
\end{aligned}
$$


From (H.10),

$$
\begin{aligned}
&-\lambda t F\left(q_{2}{ }^{*}\right)+\lambda \beta f\left(q_{2}{ }^{*}\right) q_{2}{ }^{*}+\lambda \beta \geq 0 \\
& \Longleftrightarrow-\lambda\left(t F\left(q_{2}{ }^{*}\right)-\beta f\left(q_{2}{ }^{*}\right) q_{2}{ }^{*}-\beta\right) \geq 0 \\
& \Longleftrightarrow t F\left(q_{2}{ }^{*}\right)-\beta f\left(q_{2}{ }^{*}\right) q_{2}{ }^{*}-\beta \leq 0 \\
& \Longleftrightarrow t\left(F\left(q_{2}{ }^{*}\right)-\frac{\beta f\left(q_{2}{ }^{*}\right) q_{2}{ }^{*}}{t}\right) \leq \beta \\
& \Longleftrightarrow F\left(q_{2}{ }^{*}\right)-\frac{\beta f\left(q_{2}{ }^{*}\right) q_{2}{ }^{*}}{t} \leq \frac{\beta}{t} \\
& \Longleftrightarrow F\left(q_{2}{ }^{*}\right) \leq \frac{\beta}{t}\left(f\left(q_{2}{ }^{*}\right) q_{2}{ }^{*}+1\right) \\
& \because f\left(q_{2}{ }^{*}\right) q_{2}{ }^{*} \leq 1-F\left(q_{2}{ }^{*}\right) \\
& \therefore F\left(q_{2}{ }^{*}\right) \leq 1-f\left(q_{2}{ }^{*}\right) q_{2} .
\end{aligned}
$$

So, from (H.11), if there is a certain condition satisfying

$$
F\left(q_{2}^{*}\right) \leq 1-f\left(q_{2}^{*}\right) q_{2} \leq \frac{\beta}{t}\left(1+f\left(q_{2}^{*}\right) q_{2}\right)
$$

then (H.11) will be established. And (H.12) equals

$$
\begin{aligned}
& \Longleftrightarrow 1-\frac{\beta}{t} \leq\left(\frac{\beta}{t}+1\right) f\left(q_{2}{ }^{*}\right) q_{2}{ }^{*} \\
& \Longleftrightarrow \frac{t-\beta}{t} \leq \frac{t+\beta}{t} f\left(q_{2}{ }^{*}\right) q_{2}{ }^{*} \\
& \Longleftrightarrow \frac{t-\beta}{t+\beta} \leq f\left(q_{2}{ }^{*}\right) q_{2}{ }^{*} .
\end{aligned}
$$

Obviously, when meeting $(t-\beta) /(t+\beta) \leq f\left(q_{2}{ }^{*}\right) q_{2}{ }^{*}$, (H.10) will be satisfied. Then, $w_{1}\left(q_{1}{ }^{*}\right)>w_{2}\left(q_{2}{ }^{*}\right)$.

\section{Proof of Theorem 7}

Proof. From Model 1,

$$
\beta=\frac{1}{2}+\frac{\lambda}{2 k}\left(F\left(q_{1}\right)-\frac{\int_{0}^{q} F(x) d x}{q_{1}}\right) .
$$

From Model 2, it can be obtained that

$$
t=\min \left(\frac{1}{2}+\frac{\lambda\left(F\left(q_{2}\right) q_{2}+\int_{0}^{q_{2}} F(x) d x\right)}{2 k q_{2}}, 1\right) .
$$

If $q_{2}{ }^{*}>q_{1}{ }^{*}$, then

$$
\begin{aligned}
& \left(F\left(q_{1}\right)-\frac{\int_{0}^{q} F(x) d x}{q_{1}}\right) \\
& \quad \leq\left(F\left(q_{2}\right)-\frac{\int_{0}^{q_{2}} F(x) d x}{q_{2}}\right) .
\end{aligned}
$$
$\beta<t$.

\section{Conflict of Interests}

The authors declare that there is no conflict of interests regarding the publication of this paper.

\section{Acknowledgments}

This research is supported by the National Natural Science Foundation of China (Grant no. 71372156), supported by Humanity and Social Science Youth foundation of Ministry of Education of China (Grant no. 13YJC630098), sponsored by Independent Innovation Foundation of Tianjin University. The reviewers' comments are also highly appreciated.

\section{References}

[1] J. T. Mentzer, W. DeWitt, J. S. Keebler et al., "Defining supply chain management," Journal of Business Logistics, vol. 22, no. 2, pp. 1-25, 2001.

[2] S. S. Chauhan and J.-M. Proth, "Analysis of a supply chain partnership with revenue sharing," International Journal of Production Economics, vol. 97, no. 1, pp. 44-51, 2005.

[3] S. Q. Tang, The governance structure of strategic partnerships in supply chain [Ph.D thesis], Shanghai Jiaotong University, Shanghai, China, 2006 (Chinese).

[4] S. J. Grossman and O. D. Hart, "The costs and benefits of ownership: a theory of Vertical and Lateral Integration," Journal of Political Economy, vol. 94, no. 4, pp. 691-719, 1986.

[5] H. Q. Chen, C. F. Guo, and A. Ma, "Low price strategy and sustainable development of electric appliances chain stores in China," Journal of International Business Strategy, vol. 7, no. 2, 2007.

[6] H. Demirkan and H. K. Cheng, "The risk and information sharing of application services supply chain," European Journal of Operational Research, vol. 187, no. 3, pp. 765-784, 2008.

[7] J. Faith, "Getting transfer pricing right in the recession and beyond," International Tax Review, vol. 20, no. 4, pp. 68-70, 2009.

[8] C. H. Scott and J. E. Scott, "On models for the operation of a class of electronic marketplaces," Omega, vol. 32, no. 5, pp. 373383, 2004.

[9] W.-Y. K. Chiang and G. E. Monahan, "Managing inventories in a two-echelon dual-channel supply chain," European Journal of Operational Research, vol. 162, no. 2, pp. 325-341, 2005.

[10] H. Lan, R. Li, Z. Liu, and R. Wang, "Study on the inventory control of deteriorating items under VMI model based on bilevel programming," Expert Systems with Applications, vol. 38, no. 8, pp. 9287-9295, 2011.

[11] K. Takahashi, T. Aoi, D. Hirotani, and K. Morikawa, "Inventory control in a two-echelon dual-channel supply chain with setup of production and delivery," International Journal of Production Economics, vol. 133, no. 1, pp. 403-415, 2011.

[12] A. M. Pettigrew, "Information control as a power resource," Sociology, vol. 6, no. 2, pp. 187-204, 1972.

[13] R. W. Seifert, R. I. Zequeira, and S. Liao, "A three-echelon supply chain with price-only contracts and sub-supply chain coordination," International Journal of Production Economics, vol. 138, no. 2, pp. 345-353, 2012. 
[14] J. Anselmsson and U. Johansson, "Manufacturer brands versus private brands: Hoch's strategic framework and the Swedish food retail sector," The International Review of Retail, Distribution and Consumer Research, vol. 24, no. 2, pp. 186-212, 2014.

[15] Z. Z. Qin and J. J. Yang, "Analysis of a revenue-sharing contract in supply chain management," International Journal of Logistics Research \& Applications, vol. 11, no. 1, pp. 17-29, 2008.

[16] Y. Yu, F. Chu, and H. Chen, "A Stackelberg game and its improvement in a VMI system with a manufacturing vendor," European Journal of Operational Research, vol. 192, no. 3, pp. 929-948, 2009.

[17] Y. Yu, G. Q. Huang, and L. Liang, "Stackelberg game-theoretic model for optimizing advertising, pricing and inventory policies in vendor managed inventory (VMI) production supply chains," Computers \& Industrial Engineering, vol. 57, no. 1, pp. 368-382, 2009.

[18] S. Burt and S. Davis, "Follow my leader? Lookalike retailer brands in non-manufacturer-dominated product markets in the UK," The International Review of Retail, Distribution and Consumer Research, vol. 9, no. 2, pp. 163-185, 1999.

[19] J. Raju and Z. J. Zhang, "Channel coordination in the presence of a dominant retailer," Marketing Science, vol. 24, no. 2, pp. 254$262,2005$.

[20] T. Geylani, A. J. Dukes, and K. Srinivasan, "Strategic manufacturer response to a dominant retailer," Marketing Science, vol. 26, no. 2, pp. 164-178, 2007.

[21] K. Pan, K. K. Lai, L. Liang, and S. C. H. Leung, “Two-period pricing and ordering policy for the dominant retailer in a twoechelon supply chain with demand uncertainty," Omega, vol. 37, no. 4, pp. 919-929, 2009.

[22] K. B. Chen and T. J. Xiao, "Demand disruption and coordination of the supply chain with a dominant retailer," European Journal of Operational Research, vol. 197, no. 1, pp. 225-234, 2009.

[23] G. P. Cachon, "Competitive supply chain inventory management," in Quantitative Models for Supply Chain Management, S. Tayur, R. Ganeshan, and M. Magazine, Eds., vol. 5, pp. 112-146, Kluwer Academic Publishers, Boston, Mass, USA, 1998.

[24] Y. A. Aviv and A. Federgruen, "The operational benefits of information sharing and vendor managed inventor," Working Paper, Olin School, Washington University, 1998.

[25] R. W. Seifert, U. W. Thonemann, and M. A. Sieke, "Integrating direct and indirect sales channels under decentralized decisionmaking," International Journal of Production Economics, vol. 103, no. 1, pp. 209-229, 2006.

[26] J. F. Nash, "Non-cooperative games," The Annals of Mathematics. Second Series, vol. 54, no. 2, pp. 286-295, 1951.

[27] A. E. Roth, Axiomatic Models of Bargaining, Springer, Berlin, Germany, 1979.

[28] M. Nagarajan and Y. Bassok, "A bargaining framework in supply chains: the assembly problem," Management Science, vol. 54, no. 8, pp. 1482-1496, 2008.

[29] F. Ye and Y. N. Li, "Research on buy-back contract mechanism of supply chain based on stackelberg model and nash negotiation model," Journal of Industrial Engineering and Engineering Management, vol. 3, p. 10, 2007.

[30] B. Hezarkhani and W. Kubiak, "A coordinating contract for transshipment in a two-company supply chain," European Journal of Operational Research, vol. 207, no. 1, pp. 232-237, 2010.
[31] C.-T. Zhang and L.-P. Liu, "Research on coordination mechanism in three-level green supply chain under non-cooperative game," Applied Mathematical Modelling, vol. 37, no. 5, pp. 33693379,2013

[32] J.-B. Sheu and X.-Q. Gao, "Alliance or no alliance-bargaining power in competing reverse supply chains," European Journal of Operational Research, vol. 233, no. 2, pp. 313-325, 2014.

[33] G. B. Lu, X. B. Gan, and Q. Y. Hu, "A research on three pricng scheme in a two-stage supply chain," Journal of Industrial Engineering and Engineering Management, vol. 20, no. 1, pp. 1217, 2006.

[34] Y. H. Wei, Q. Y. Hu, and C. Xu, "Ordering, pricing and allocation in a service supply chain," International Journal of Production Economics, vol. 144, no. 2, pp. 590-598, 2013.

[35] X. Wang, X. Wang, and Y. Su, "Wholesale-price contract of supply chain with information gathering," Applied Mathematical Modelling, vol. 37, no. 6, pp. 3848-3860, 2013.

[36] H. Yu and L. Liu, "Impact analysis on supply chain performance based on the pricing power transferring of the whole price," System Engineering-Theory and Practice, vol. 29, no. 5, pp. 11-16, 2009.

[37] S. Johansen and T. Lange, "Least squares estimation in a simple random coefficient autoregressive model," Journal of Econometrics, vol. 177, no. 2, pp. 285-288, 2013.

[38] E. Iossa and D. Martimort, "The simple microeconomics of public-private partnerships," Journal of Public Economic Theory, vol. 17, no. 1, pp. 4-48, 2015.

[39] L. Greco, "Imperfect bundling in public-private partnerships," Journal of Public Economic Theory, vol. 17, no. 1, pp. 136-146, 2015.

[40] G. P. Cachon, "Supply chain coordination with contracts," in Handbooks in Operations Research and Management Science, 11: Supply Chain Management: Design, Coordination and Operation, pp. 229-339, 2003. 


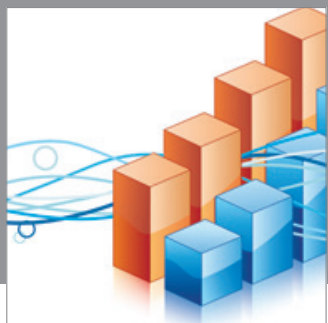

Advances in

Operations Research

mansans

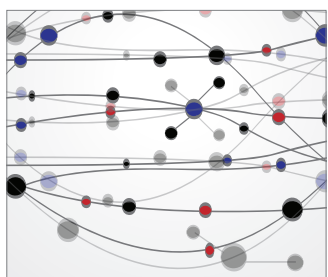

The Scientific World Journal
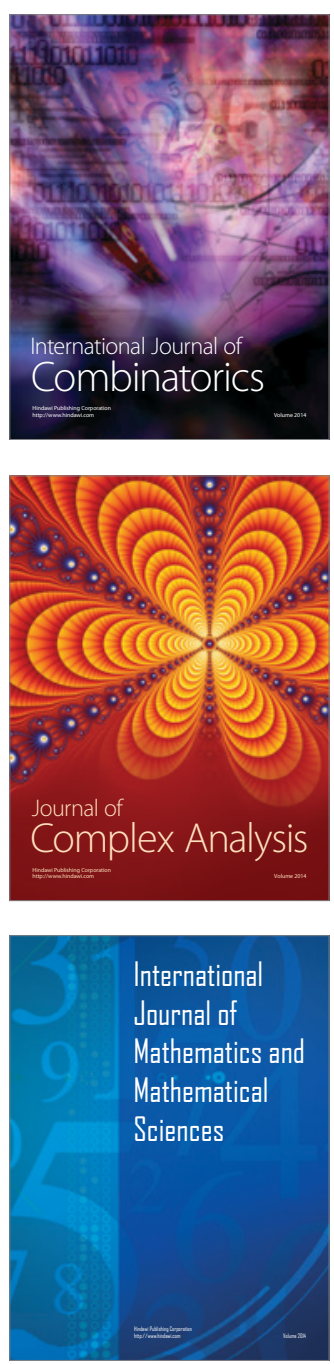
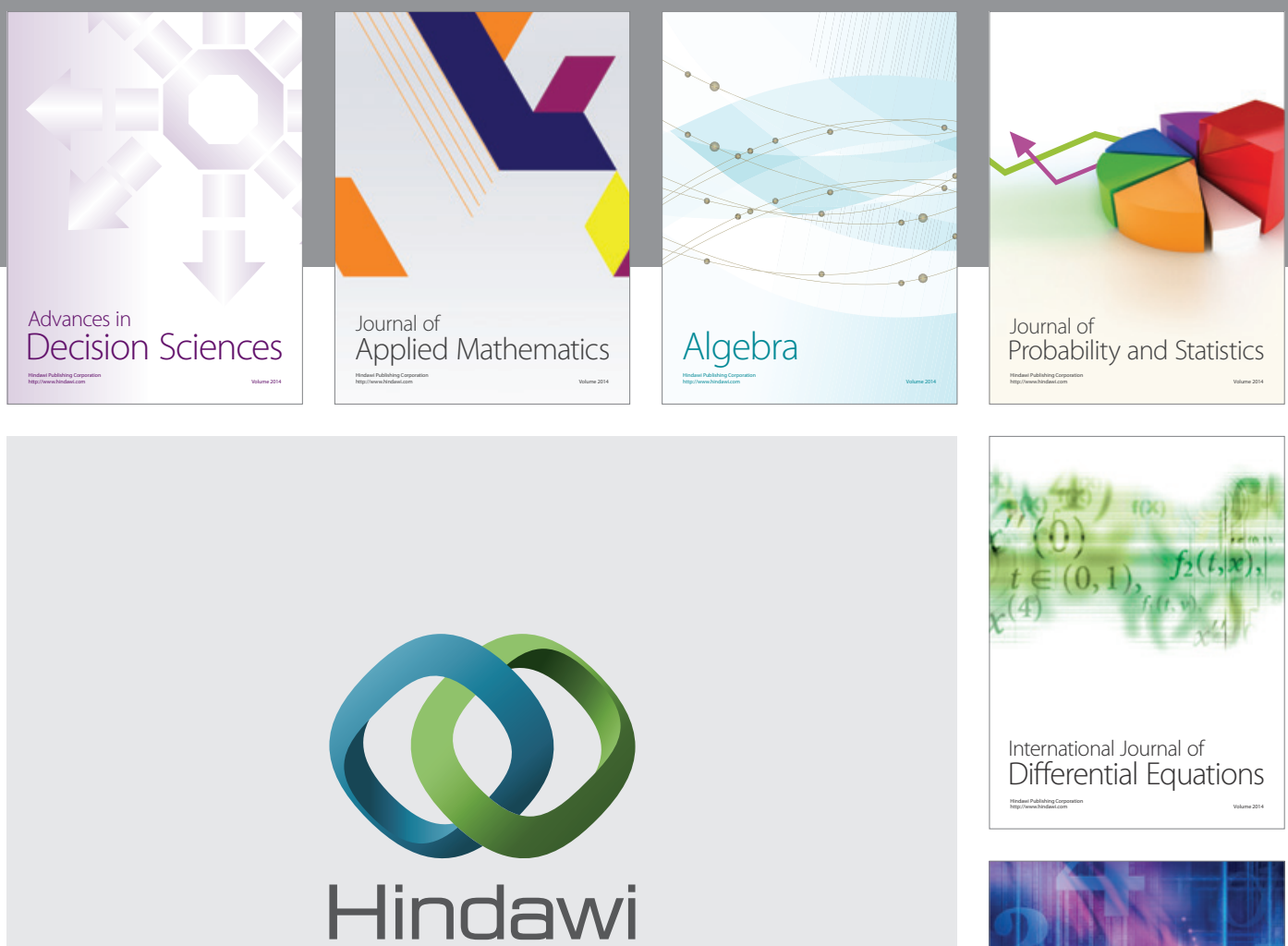

Submit your manuscripts at http://www.hindawi.com
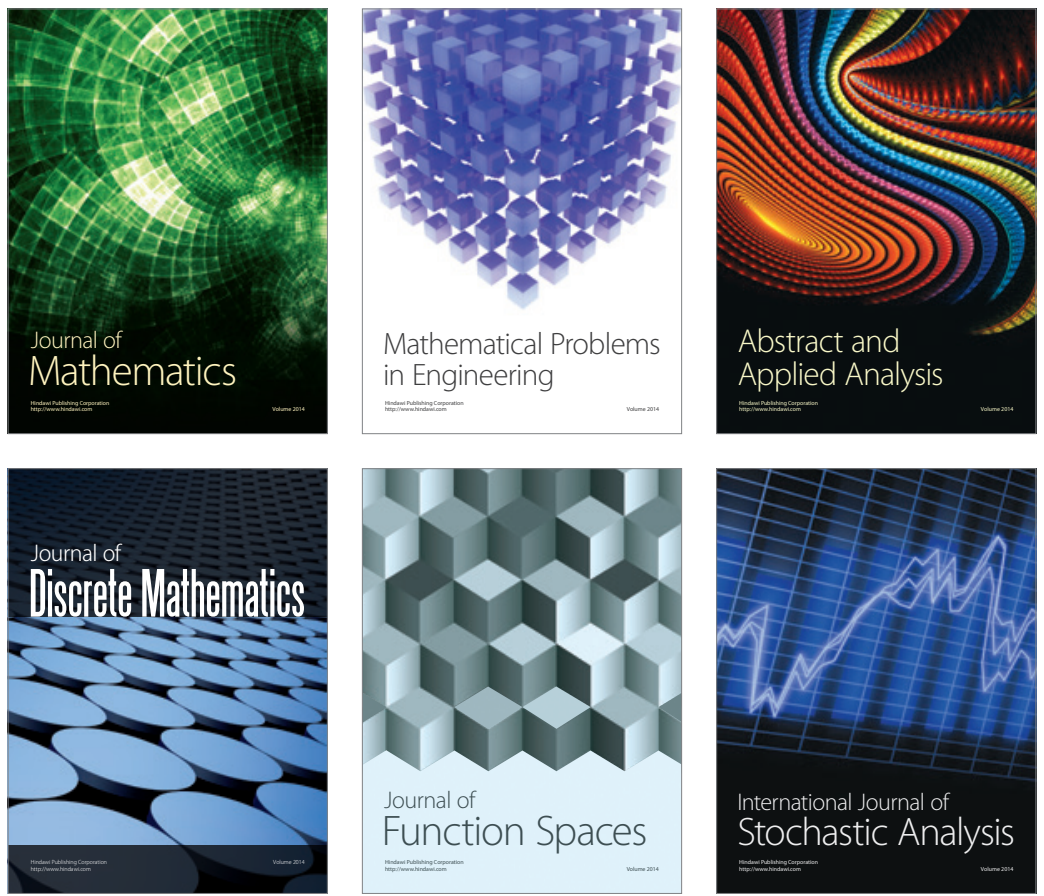

Journal of

Function Spaces

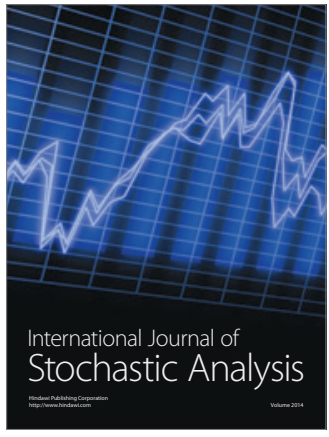

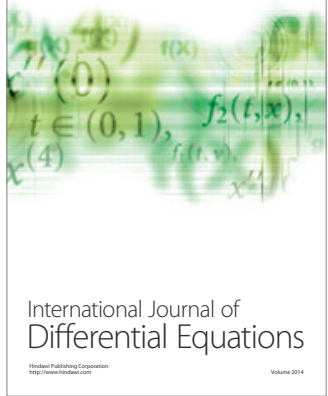
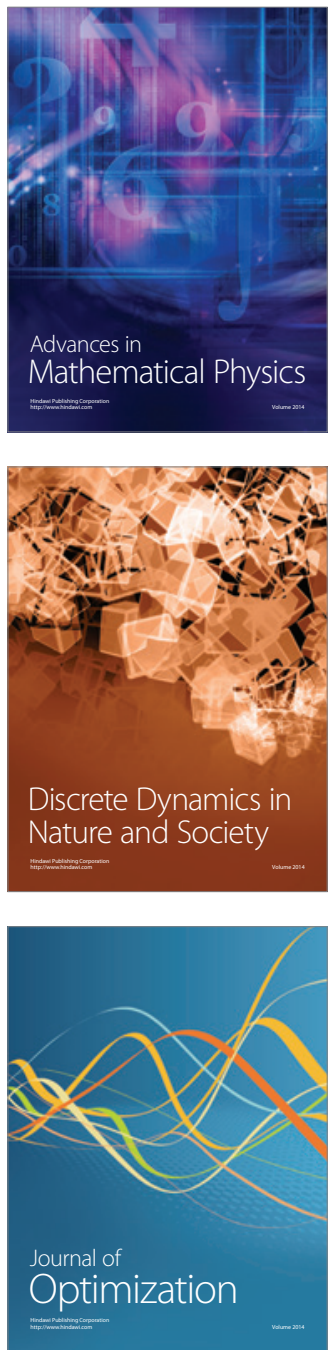